Article

\title{
Risk Assessment System Based on WebGIS for Heavy Metal Pollution in Farmland Soils in China
}

\author{
Shouhui Pan ${ }^{1}$, Kaiyi Wang ${ }^{1, *}$, Li Wang ${ }^{2, *}$, Zhibin Wang ${ }^{1}$ and Yanyun Han ${ }^{1}$ \\ 1 Beijing Research Center for Information Technology in Agriculture, Beijing Academy of Agriculture and \\ Forestry Sciences, Beijing 100097, China; pansh@nercita.org.cn (S.P.); wangzb@nercita.org.cn (Z.W.); \\ hanyy@nercita.org.cn (Y.H.) \\ 2 School of Economics and Management, Beihang University, Beijing 100191, China \\ * Correspondence: wangky@nercita.org.cn (K.W.); wlbh@vip.163.com (L.W.); \\ Tel.: +86-10-51503722 (K.W. \& L.W.)
}

Received: 27 August 2017; Accepted: 12 October 2017; Published: 19 October 2017

\begin{abstract}
Heavy metal pollution in farmlands is a serious threat to sustainable agricultural development and has become a major agro-ecological problem that has attracted public concern in China. This study proposes a soil-crop collaborative risk assessment model that aims to assess the potential safety risks of heavy metal pollution in farmland soils by considering the concentrations of heavy metals in soils and the accumulation effects of heavy metals in crops. Based on these effects, a decision support system for risk assessment of heavy metal pollution in farmland soil is established, in which technologies such as web-based geographic information system, quick response code, radio frequency identification, and web service are introduced as the bases. The proposed system is composed of a mobile data acquisition terminal (MDAT) and a web-based information system (WIS). The MDAT, which is a portable computerized device running on the Android platform, is used for data acquisition or query, and the WIS is used for risk assessment, data management, and information visualization. The system is employed in some county-level cities in China for risk assessment and supervision of heavy metal pollution in farmlands. The practical application results show that the system provides highly efficient decision support for risk assessment of heavy metal pollution in farmland soils.
\end{abstract}

Keywords: decision support system; heavy metal pollution; farmland soil; WebGIS

\section{Introduction}

China has experienced rapid economic growth in the past nearly 40 years because of their reform and opening-up policy and became the world's second largest economy behind the USA in 2010 [1]. However, the country is still confronted with increasingly serious environmental pollution problems [2-4], especially heavy metal pollution in water and soil [5-8], which has been identified as the main cause of cancer [9]. Heavy metals, such as cadmium (Cd), mercury (Hg), arsenic (As), lead $(\mathrm{Pb})$, chromium $(\mathrm{Cr})$, zinc $(\mathrm{Zn})$, copper $(\mathrm{Cu})$, cobalt $(\mathrm{Co})$, and nickel $(\mathrm{Ni})$, can pose a serious hazard to the environment and human health [10]. Although some of them, such as $\mathrm{Zn}, \mathrm{Cu}$, and $\mathrm{Co}$, are essential trace elements in the human body within a certain safety threshold [5], most of the metals are classified as highly cytotoxic, carcinogenic, and mutagenic by the International Agency for Research on Cancer even at low concentrations [5,11]. Previous studies showed that excessive $\mathrm{Pb}$ and $\mathrm{Hg}$ can permanently damage the nervous system and brain and that the accumulation of $\mathrm{Cd}$ and As has toxic effects on the liver, lung, kidney, and skin [12,13]. 
Farmland soils are the basis of agricultural production, and their environmental condition is closely related to the quality and safety of agricultural products and human health [10,14-16]. Heavy metal pollution in farmlands is an important issue as it is closely linked to the human food chain $[5,7,15]$. Heavy metal pollution in farmlands cause decreased quality and safety incidents in agricultural products. Many agricultural product incidents, such as the blood $\mathrm{Pb}$ contamination in Hunan [17], $\mathrm{Cd}$ pollution in Guangxi [18], and Cd-tainted rice in Hunan 2013 [5,19], have occurred across China due to heavy metal pollution in farmlands, which has recently become a major agro-ecological problem that has attracted public concern. This problem is a serious threat to the sustainable development of modern agriculture and socio-economy, the agro-ecological environment, and the quality and safety of agricultural products.

Currently, the study of heavy metal pollution in farmlands has become the focus of attention of the government and the public. In April 2014, the Ministry of Environmental Protection of China (MEPC) and the Ministry of Land and Resources of China jointly released the results of a national survey on soil pollution and soil quality, which showed that $19.4 \%$ of the samples collected from the surveyed farmlands were polluted [20]. In May 2016, the State Council of China released an action plan for soil pollution control, which provides comprehensive and strategic arrangements for the prevention and control of soil pollution in China [21]. Subsequently, the MEPC and other ministries and local governments have performed a series of active measures for preventing and controlling soil pollution and achieved some success [21].

Meanwhile, heavy metal pollution has also attracted the attention of local and international scholars. Hu et al. [5] reviewed the current status and related public policies of heavy metal pollution in China and presented a few countermeasures for preventing heavy metal pollution. Ding et al. [6] investigated historical changes and spatial variations in metal concentrations in Chinese composts by analyzing representative compost samples and published data. Some studies showed that heavy metal pollution in farmland soils is mainly from $\mathrm{Cd}, \mathrm{Hg}, \mathrm{Cu}$, and $\mathrm{Ni}$ and that $\mathrm{Cd}$ is the main pollutant in farmland soils in China, with the highest pollution rate among these pollutants of $7.75 \%$ [22]. Si et al. [14] indicated that long-term irrigation with polluted Yellow River water leads to metal accumulation in local farmland soils and spring wheat. Wan et al. [15] proposed a remediation method for contaminated soil by planting mulberry trees instead of rice based on their risk assessment. Tang et al. [23] proposed a novel ecological hydraulic remediation technique for soils contaminated by heavy metals that integrates the advantages of chemical elution, solidification, phytoremediation, and field management.

Numerous methods can be used to assess heavy metal pollution with regard to risk assessment [24-27]. Some common methods include the single-factor pollution index [24], Nemerow pollution index (NPI) [25-27], enrichment factor (EF) [24,26,27], potential ecological risk index (PERI) [26-28], geoaccumulation index (Igeo) [24,26,27], and contamination security index (CSI) [24]. Cai et al. [26] compared the abovementioned methods and discussed their use in the assessment of soils in relation to heavy metal pollution using empirical and real-world data. A comprehensive assessment of heavy metal pollution in the topsoil of a historical urban park was conducted using the NPI, EF, Igeo, PERI, and CSI pollution indices [24]. Xiao et al. [25] used the Igeo, PERI, hazard index, and carcinogenic risk index to assess and determine the human health risk of heavy metals in urban soils from a steel industrial district in China. Qu et al. [7] presented a health risk assessment procedure for heavy metal pollution using the Monte Carlo simulation technique that they based on the U.S. Environmental Protection Agency model and concluded that $\mathrm{Pb}$ poses a significant cumulative non-carcinogenic risk to workers [7]. Li et al. [19] used spatial statistical methods to examine the underlying socioeconomic and physical factors behind water pollution. Potential health risk expressed as a hazard quotient was used to assess the environmental impact and site-specific health risks of chromium $(\mathrm{Cr})$ via direct and indirect exposure assessment methods [29]. In the study of Chen et al. [27], several pollution indicators were used to evaluate pollution levels, and Monte Carlo simulation was used to analyze the 
uncertainty of the health risk model. The principles of these methods differ, and each method has its own strengths and weaknesses [26,28].

In addition, many scholars have applied geographic information system (GIS) technology for analyzing and visualizing spatial data on heavy metal pollution [30-34]. For example, Carr et al. [30] created spatial distribution maps, 3D images, and interpretive hazard maps for heavy metal pollution using GIS techniques. Shan et al. [32] used GIS to display principal component analysis results spatially to investigate the influence of land use on heavy metal accumulation. Amous and Hassan used GIS techniques for evaluating heavy metal risk in water [33]. The abovementioned studies are important in controlling heavy metal pollution in farmland soils.

However, the corresponding information system for heavy metal pollution in farmland soils is outdated, thereby leading to insufficient effective risk assessment or supervision of heavy metal pollution in farmland soils. With the rapid growth of heavy metal pollution monitoring data, an intelligent management information system should be established by using current advanced information technologies to effectively integrate massive amounts of data for data sharing, data mining [35], and decision support [36,37]. In this study, a decision support system based on web-based GIS (WebGIS) for risk assessment of heavy metal pollution in farmland soils is constructed and aims to assess the potential safety risk in farmland soils. Through our system, we can realize convenient data collection, rapid data query, and risk assessment of heavy metal pollution in farmland soils.

\section{Framework for Decision Support of Risk Assessment}

Decision support theory, methods, and algorithms have been discussed by many researchers in the literature [36-43]. In this study, a decision support system for risk assessment of heavy metal pollution in farmland soils (DSS-RAHMP) is proposed (Figure 1) and can be used for common risk assessment practices for heavy metal pollution in farmland soils.

As shown in Figure 1, the framework can be divided into four layers from an architectural point of view: (1) infrastructure; (2) business application; (3) presentation; and (4) user layers. The infrastructure layer is used to provide infrastructure support for the risk assessment of heavy metal pollution; this layer includes data storage and web application services, load balance, and virtualization. The business application layer is used to provide users with various application services, such as risk assessment, data query and update, statistical analysis, agricultural survey, and information virtualization. The presentation layer is responsible for formatting and displaying information from the business application layer. The user layer offers various user interfaces, such as desktop computers, laptops, and tablet personal computers (PCs), through which users can access the system.

Moreover, the DSS-RAHMP is composed of: (a) a mobile data acquisition terminal (MDAT); and (b) a web-based information system (WIS). The MDAT is an Android-based portable computerized device that runs a data acquisition system for data acquisition or query. The WIS, which is the core of the DSS-RAHMP, is used for risk assessment, data management, and data query. 


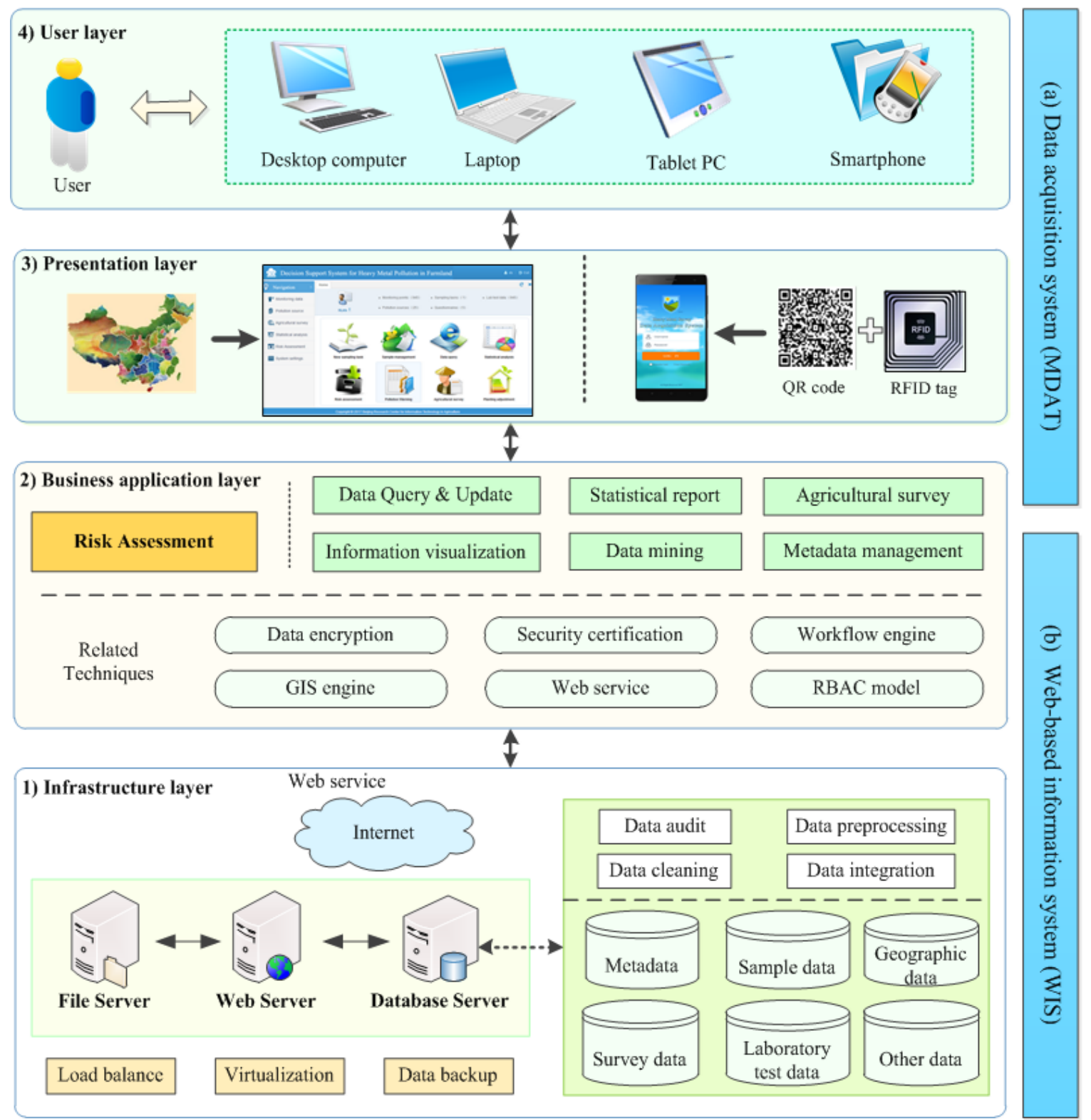

Figure 1. Decision support system for risk assessment of heavy metal pollution in farmland soils (DSS-RAHMP).

\subsection{Three-Layered Software Architecture Model}

A three-layered software architecture model is used to build the WIS and MDAT, which are both based on a model view controller (MVC) [44], to make the system open, flexible, scalable and reusable. Design patterns are proposed through the integration of integrated Spring MVC [45], Hibernate 4.2 [46], Struts 2.3.1 [47], SiteMesh 3 [48], and Maven 3.5.0 [49]. Figure 2 divides the three-layered software architecture model into four parts: the presentation layer (PL), business logic layer (BLL), data access layer (DAL), and model. The PL provides the user interface of the system and typically uses a controller and Java server pages (JSPs)/Views for browser-based/Android-application-based interactions, respectively; the controller is responsible for forwarding requests, and the JSPs/Views are responsible for displaying the web page to the user. The BLL separates the DAL from the PL and serves as an intermediary for data exchange between the two layers. The BLL implements the business functionality of the system, which is typically composed of services implemented using Java programming language. The DAL is responsible for exposing the data stored in the database to the 
BLL, thereby isolating the BLL from the details of the specific data storage solution; this isolation can minimize the effect of changes in database provider or schema. The model is an object-oriented entity or a data container that encapsulates and conceals the details of the specific data representation formats. This proposed three-layered software architecture model has high cohesion, reusability, and scalability, low coupling, and easy deployment and maintenance characteristics.

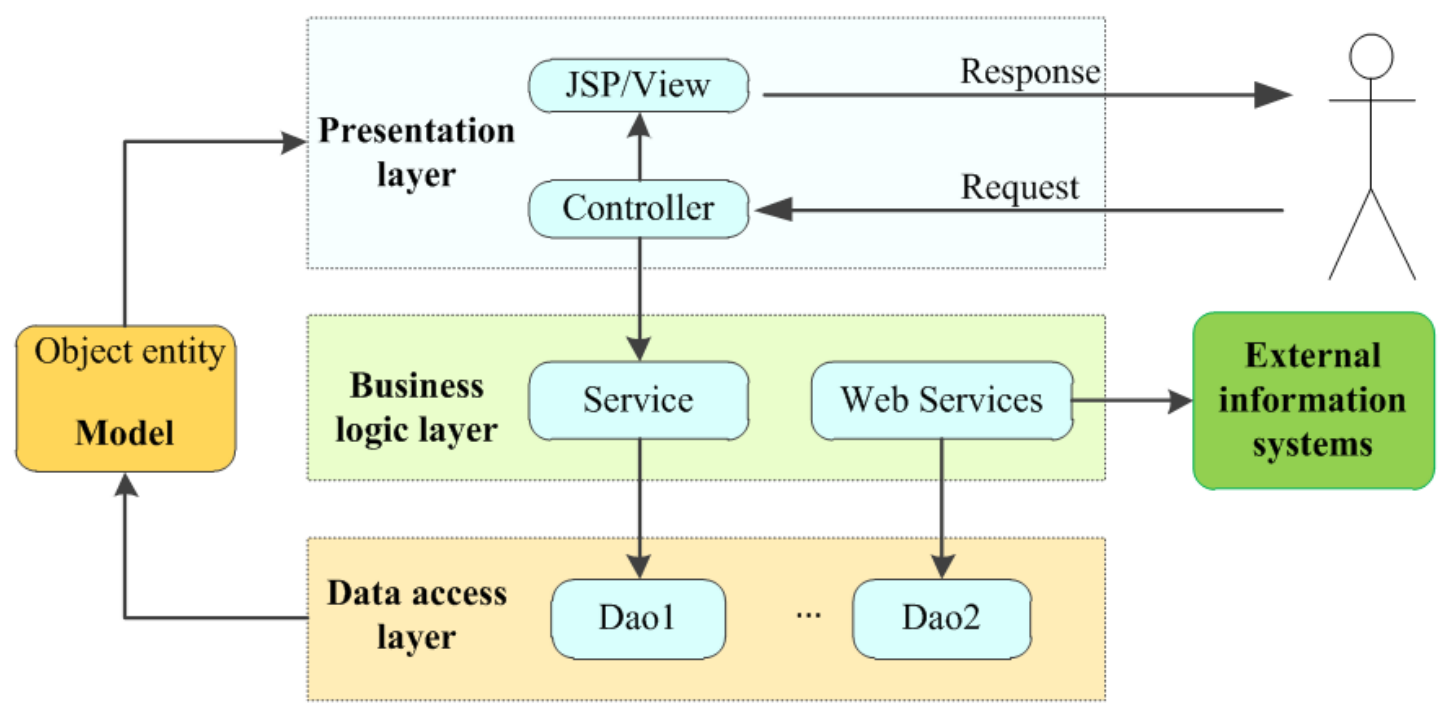

Figure 2. Structure of three-layered software architecture model.

\subsection{Data Acquisition and Management}

\subsubsection{Data Acquisition}

A data acquisition system for heavy metal pollution in farmlands running on an MDAT, that is, a smartphone application (Figure 3), is developed using the Android platform with Java programming language to collect data quickly and conveniently [50]. Android Software Development Kit 23.0.0 and Android Studio 2.3, which is the official integrated development environment for the Android platform, are utilized in the development of this smartphone application. Figure 3 shows the four functional modules of the data acquisition system: pollution source tagging, data collection monitoring, questionnaire survey, and system settings. The data acquisition system can exchange data with the WIS using web service. Data acquisition personnel can easily record sampling information on a mobile phone and report data in real time with this data acquisition system.

In addition, quick response (QR) code, radio frequency identification (RFID), near-field communication (NFC), and 4G mobile technologies are integrated in the data acquisition system. The ID of a sample can be quickly obtained by the data acquisition system by scanning QR codes or RFID tags. Thus, this identifier is valuable in improving the efficiency of data acquisition. 


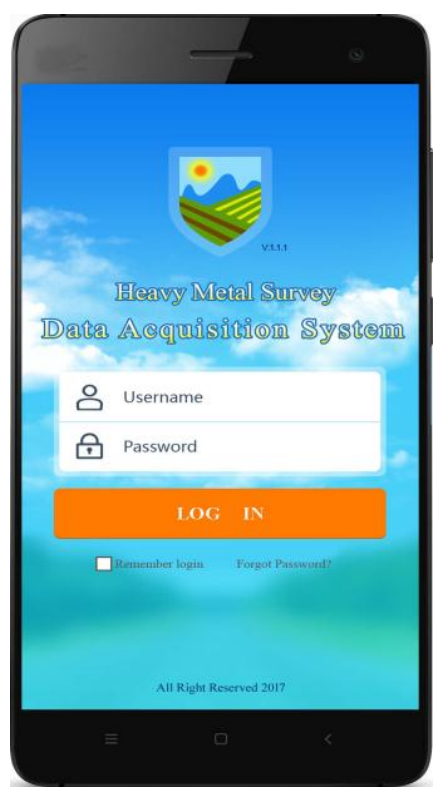

(a)

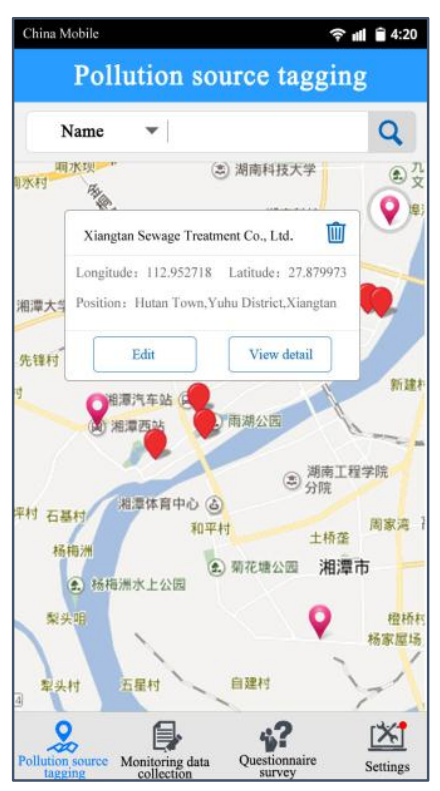

(b)

Figure 3. Data acquisition system for heavy metal pollution in farmlands running on MDAT: (a) login page of data acquisition system; and (b) main interface of data acquisition system.

\subsubsection{Data Management}

As the core of the DSS-RAHMP, the WIS is responsible for data processing and storage. All data uploaded by the MDAT can be processed by the WIS. The WIS is developed in Java programming language [50] and is based on a three-layered software architecture model that runs on Tomcat 7.0 web server and supports Java Development Kit 1.7 or later. In addition, the WebGIS technology, that is, Baidu Maps, is utilized for displaying the monitoring data dynamically and visually in the WIS.

The main functional modules of the WIS are risk assessment, data management monitoring, pollution source management, agricultural survey, statistical analysis, and system settings. In the data management monitoring module, we can create new sampling tasks, assign them to the data acquisition personnel, and audit the monitoring data uploaded by the MDATs. In the pollution source management module, we can visually add pollution sources and monitoring points to the map. Meanwhile, many data mining methods are integrated into the statistical analysis module, and various data reports from multiple dimensions can be generated. The agricultural survey module can be used for various surveys, such as those for heavy metal pollution investigation and the intention of farmers to plant crops. Finally, the risk assessment of heavy metal pollution in farmland soils is conducted in the risk assessment module, which is based on our proposed soil-crop collaborative model (Section 3).

\subsection{Key Technologies}

\subsubsection{WebGIS}

GIS is a computing system that can store, manipulate, analyze, and display spatial and geographic data [30]. GIS technology can support rapid spatial orientation, location retrieval, and information visualization in the risk assessment process of heavy metal pollution in farmlands. WebGIS is the junction of web technology and GIS, thereby improving and extending the functionality of GIS. WebGIS is a distributed system that provides geographic information services that are based on Internet or intranet platforms and allows users to access geographic data and processing services only with web browsers. Thus, WebGIS has strong interactivity and dynamics. Compared with traditional GIS software, WebGIS has lower application threshold, wider application range, more timely data update, lower construction cost, and higher security. Many large Internet companies, such as Google, Baidu, 
and Tencent, recently developed online maps that are based on WebGIS technology for public use. In this study, Baidu Maps is used for visually displaying the pollution risk level and the detail of each monitoring point on the map.

\subsubsection{QR Code and RFID}

QR code [51,52] is the trademark for a type of 2D barcode. RFID [52,53] uses electromagnetic fields for automatically identifying and tracking tags attached to objects. In this study, QR code and RFID technologies are used for sample identification by scanning barcodes or reading RFID tags with smartphones. An RFID or a QR code tag, shown in Figure 4a, is attached to a sample bag. The QR code tag can be scanned by a smartphone camera, and the RFID tag can be read by the built-in NFC module of a smartphone.

To ensure the authenticity and normality of the collected samples, a unified sample coding method that can generate a unique ID for each sample is designed. The ID code of each sample consists of 20 digits, which is divided into three parts, project information, regional code, and serial number, which is further subdivided into eight parts (Figure $4 \mathrm{~b}$ ). When assigning a sampling task, the system automatically generates and prints the QR code tags for the samples to be collected. When collecting the soil or crop samples, the data acquisition personnel can quickly enter the sample code, which can automatically associate with and bind monitoring points by scanning the QR code or RFID tag embedded on the sample bag using a smartphone. This type of collection method considerably improves the efficiency of data acquisition and reduces workload. Thus, this method can be considered a highly efficient solution.

\begin{tabular}{|l|l|c|}
\hline & Sanple ID & 17030143030400541200 \\
\cline { 2 - 3 } & Project & $\begin{array}{c}\text { Heavy metal survey in } \\
\text { Xiangtan in } 2017\end{array}$ \\
\cline { 2 - 3 } & Sample Type & soil | rice \\
\cline { 2 - 3 } & Remark & Cha En Si Town \\
\hline
\end{tabular}

(a)

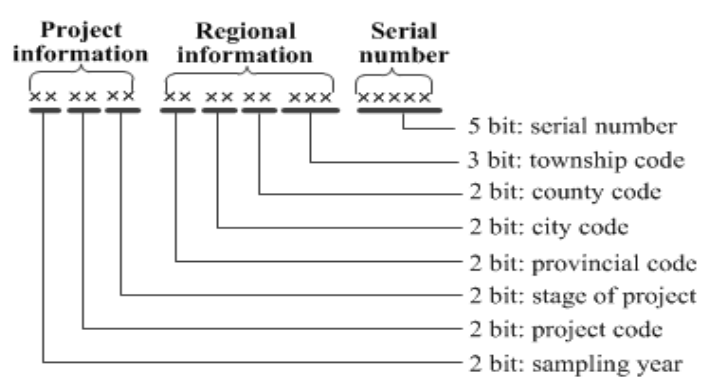

(b)

Figure 4. QR code tag of sample and coding structure of sample ID: (a) QR code tag of sample; and (b) coding structure of sample ID.

\subsubsection{Web Service}

Web service is the service provided by an information system to another [54] by communicating with each other via the Internet or intranet, thereby describing a standardized way of integrating web-based interfaces using extensible markup language, simple object access protocol, web services description language, and universal description, discovery, and integration open standards. In this paper, web service technology is used for data exchange between the WIS and the MDAT equipment or between the WIS and other external information systems. Thus, this decision support system has good openness and high scalability.

\section{Risk Assessment Model for Heavy Metal Pollution}

\subsection{Traditional Soil Heavy Metal Risk Assessment Model}

In this study, a risk assessment model that only considers the concentration of soil sample is first presented. This model is called the traditional soil heavy metal risk assessment model and uses 
the single-factor pollution index (SFPI) and Nemerow pollution index (NPI) to evaluate heavy metal pollution in farmland soils [24,25]. SFPI refers to the single pollution index of particular heavy metals in farmland soils, whereas NPI is a multifactor environmental quality index that considers extreme values and is frequently used to assess the degree of soil pollution [25]. The SFPI is obtained by the measured concentration of each heavy metal divided by its limited value in the farmland soil. The formula is as follows:

$$
S_{k}=\frac{S C_{k}}{S L_{k}}
$$

where $S_{k}, S C_{k}$, and $S L_{k}$ are the single pollution index, measured concentration, and limit value of the $k$ th heavy metal in the farmland soil, respectively, and can be obtained according to relevant technical standards. Then, the soil pollution index of each monitoring point can be obtained by the NPI model, which is calculated by the following equation:

$$
\text { PIS }_{i}=\sqrt{\frac{\left(\frac{1}{m} \sum_{k=1}^{m} S_{i k}\right)^{2}+\left(S_{i \max }\right)^{2}}{2}}
$$

where $P I S_{i}$ is the soil pollution index of the $i$ th monitoring point, $S_{i k}$ is the single pollution index of the $k$ th heavy metal in the soil of the $i$ th monitoring point, $m$ is the number of studied heavy metals, and $S_{i \max }$ is the maximum value of the single pollution index for all the heavy metals in the $i$ th monitoring point, which is described as follows:

$$
S_{i \max }=\max \left\{S_{i 1}, \cdots, S_{i k}, \cdots, S_{i m}\right\}
$$

The pollution degree of the monitoring point is categorized by the Chinese environmental protection industry standard "The Technical Specification for Soil Environmental Monitoring (HJ/T 166-2004)", which is presented in Table 1.

Table 1. Pollution grade of heavy metals in farmland soil of each monitoring point.

\begin{tabular}{ccc}
\hline Soil Pollution Index & Pollution Grade & Description \\
\hline$P I S_{i} \leq 0.7$ & I & Excellent \\
$0.7<P I S_{i} \leq 1.0$ & II & Good \\
$1.0<P I S_{i} \leq 2.0$ & III & Lightly Polluted \\
$2.0<P I S_{i} \leq 3.0$ & IV & Moderately Polluted \\
$P I S_{i}>3.0$ & V & Severely Polluted \\
\hline
\end{tabular}

\subsection{Soil-Crop Collaborative Risk Assessment Model}

Previous studies showed that the transfer and accumulation characteristics of heavy metals in different soil-crop systems are different $[55,56]$. Therefore, the accumulation effects of heavy metals in crops should be considered when evaluating the pollution degree of heavy metals in farmland soils. This study proposes a soil-crop collaborative assessment model that considers the bioaccumulation of heavy metals in crops in the evaluation of heavy metal pollution in farmlands. In other words, the soil sample of each monitoring point and its corresponding crop sample are jointly used for assessing the pollution degree in the monitoring point.

The crop and soil samples are evaluated similarly. Let $C_{k}$ denote the single pollution index of the $k$ th heavy metal in crops, which is expressed as follows:

$$
C_{k}=\frac{C C_{k}}{C L_{k}}
$$


where $C C_{k}$ is the measured concentration of the $k$ th heavy metal in the crop and $C L_{k}$ is the limit value of the $k$ th heavy metal in the crop, which can be determined by the Chinese national standard "National Standards for Food Safety-Maximum Limits of Pollutants in Foods (GB 2762-2017)." Then, we can obtain the crop pollution index of the $i$ th monitoring point, which is defined as:

$$
\text { PIC }_{i}=\sqrt{\frac{\left(\frac{1}{m} \sum_{k=1}^{m} C_{i k}\right)^{2}+\left(C_{i \max }\right)^{2}}{2}}
$$

where $P I C_{i}$ is the crop pollution index of the $i$ th monitoring point, $C_{i k}$ is the single pollution index of the $k$ th heavy metal in the crops of the $i$ th monitoring point, $m$ is the number of studied heavy metals, and $C_{i \max }$ is the maximum value of the single pollution index for all the heavy metals in the crops of the $i$ th monitoring point, which is expressed as:

$$
C_{i \max }=\max \left\{C_{i 1}, \cdots, C_{i k}, \cdots, C_{i m}\right\}
$$

Then, the pollution index of each monitoring point is determined by the combination of soil and crop pollution indices, which is defined as:

$$
P I_{i}=\alpha \times P I S_{i}+\beta \times P I C_{i}
$$

where $\alpha+\beta=1$ and $\alpha$ and $\beta$ are the weights of PIS $_{i}$ and PIC $_{i}$, respectively, which indicate the importance of soil samples and crop samples, respectively, in the assessment of heavy metal pollution in farmland soils. The values of $\alpha$ and $\beta$ are determined by domain experts. Previous studies show that heavy metals mainly harm farmland soils through their absorption by crops, which leads to quality and safety problems for agricultural products $[5,7,15]$. In this study, we selected three experts on soil heavy metal pollution control to determine the values of $\alpha$ and $\beta$. Three experts agree that the concentrations of heavy metals in crops should be treated the same way as in soils. Thus, we set $\alpha=\beta=0.5$ in this study. High levels of pollutants in soils or crops could be smoothened by the average; nevertheless, to a certain extent, this average can more effectively reflect the damage of heavy metal pollution to the soil in comparison with the sole consideration of soil samples. The values of $\alpha$ and $\beta$ can be dynamically adjusted based on expert opinions.

Finally, the pollution degree in the monitoring point can be obtained and evaluated using five levels (Table 2).

Table 2. Pollution degree of heavy metals in farmland soil of each monitoring point.

\begin{tabular}{cccc}
\hline No. & Pollution Index & Pollution Level & Description \\
\hline 1 & $P I_{i} \leq 0.7$ & I & Excellent \\
2 & $0.7<P I_{i} \leq 1.0$ & II & Good \\
3 & $1.0<P I_{i} \leq 2.0$ & III & Lightly Polluted \\
4 & $2.0<P I_{i} \leq 3.0$ & IV & Moderately Polluted \\
5 & $P I_{i}>3.0$ & V & Severely Polluted \\
\hline
\end{tabular}

\section{Results and Discussion}

\subsection{Study Area and Data}

\subsubsection{Study Area}

Xiangtan County in Hunan Province, which is well-known as the hometown of nonferrous metals, is used as the study area for verifying our proposed model. Xiangtan County is in the lower reaches of Xiang River, which covers an area of approximately $2132 \mathrm{~km}^{2}$ and is within N 27.333-28.083 and E 
112.416-113.049. A total of 945 monitoring points are used, and their spatial distribution is shown in Figure 5. Most of these monitoring points are in the middle east of this county, and a small amount is in the south of this district, which has a good distribution of rice fields. The 945 monitoring points are distributed among the 285 administrative villages of 15 towns and seven townships of the county.

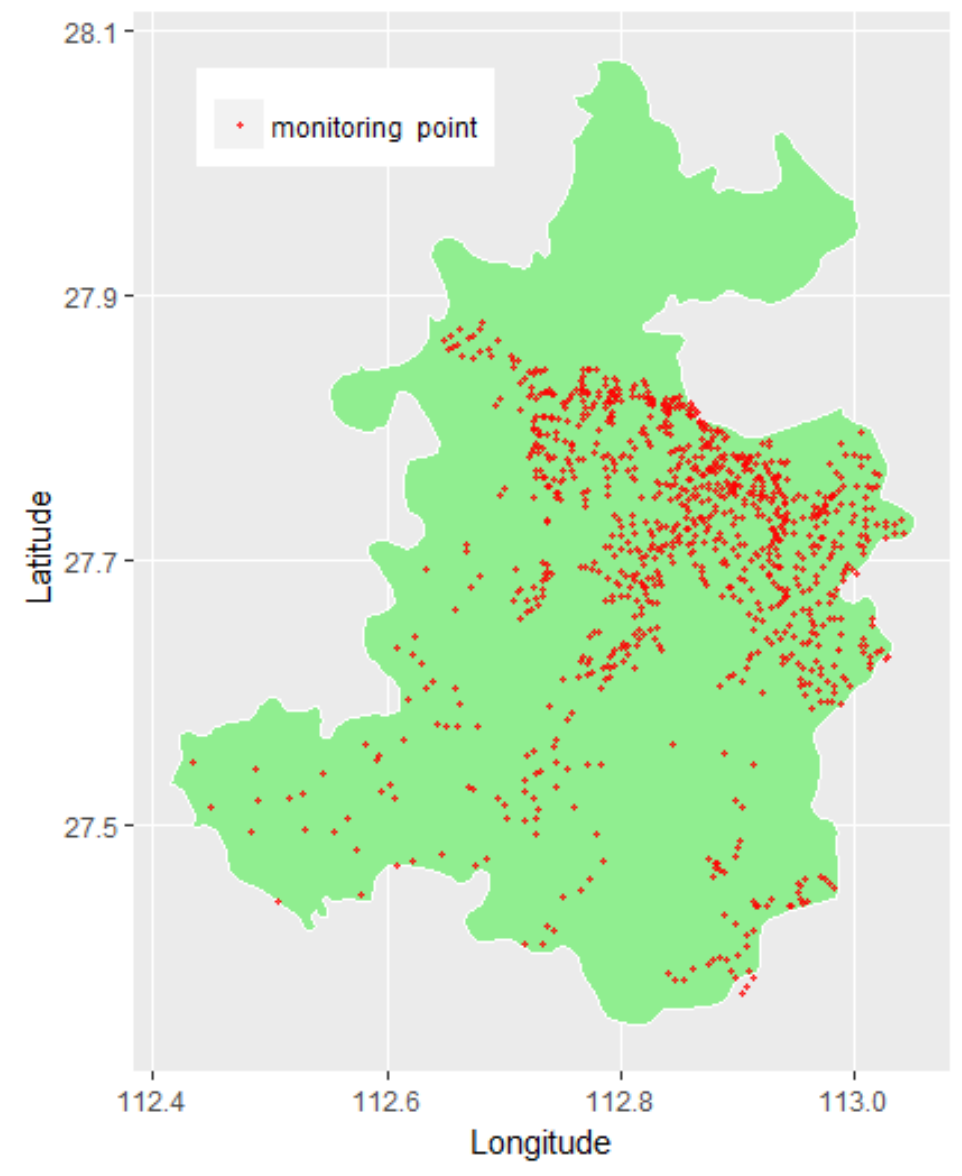

Figure 5. Spatial distribution of monitoring points.

\subsubsection{Data}

This study examines data on five types of heavy metals, namely, $\mathrm{Cd}, \mathrm{Hg}$, $\mathrm{As}, \mathrm{Pb}$, and $\mathrm{Cr}$, which are commonly related to human health and are the main causes of heavy metal pollution in farmland soils in China according to a national survey of soil pollution on soil quality released by the Chinese government department in 2014 [20]. We select rice as the crop sample because it is the main cultivated crop in the area. A soil sample $(0-20 \mathrm{~cm})$ and a corresponding rice sample are collected from each of the 945 monitoring points. The latitude and longitude of each monitoring point and its soil type, land utilization, farming, irrigation, sampling scene pictures, and surrounding potential pollution sources are recorded and uploaded to the WIS synchronously by using our developed data acquisition system. All soil and rice samples are transported to the laboratory in sealed plastic bags for laboratory testing. The test results are imported into the WIS promptly after testing.

\subsection{Sample Characteristics}

A descriptive statistical summary of the concentrations of the heavy metals in the soil and rice samples (Table 3) is obtained using DPS software (Hangzhou Rui Feng Information Technology Co., Ltd.: Hangzhou, China) [57], which is the commonly used statistical analysis software in China. Table 3 shows that the median concentrations of $\mathrm{Cd}, \mathrm{Hg}, \mathrm{As}, \mathrm{Pb}$, and $\mathrm{Cr}$ in the soil are $0.55,0.15,17.10,44.30$, 
and $70.50 \mathrm{mg} / \mathrm{kg}$, respectively. Similarly, the median concentrations of $\mathrm{Cd}, \mathrm{Hg}, \mathrm{As}, \mathrm{Pb}$, and $\mathrm{Cr}$ in the rice are $0.28,0.01,0.08,0.00$, and $0.08 \mathrm{mg} / \mathrm{kg}$, respectively. The median and mean concentrations of the heavy metals in the soil and rice are close, thereby indicating that the distribution concentrations of the heavy metals in soil and rice are approximately symmetrical. The maximum and minimum values of $\mathrm{Cd}$ in the soil are 128.40 and 0.17 , respectively, which has a difference of approximately 755 times. Meanwhile, the differences between the maximum and minimum values of $\mathrm{Hg}, \mathrm{As}, \mathrm{Pb}$, and $\mathrm{Cr}$ in the soil are approximately 22, 29, 12, and 8 times, respectively. The minimum value of each heavy metal except $\mathrm{Cd}$ is close to 0 ; that of $\mathrm{Cd}$ is 6.21 , which is high. The coefficient of variations (CVs) of the heavy metals in the soil are 34.33-461.42\%, and those in the rice are $42.59-233.46 \%$. The kurtosis of each data item (except $\mathrm{Hg}$ in rice) is greater than 0 . Notably, the data item for $\mathrm{Cd}$ in the soil has a high kurtosis, thereby indicating that its distribution has extreme values. The skewness of all data items are greater than 0 , thereby indicating that their distributions have the exact skewness. The median and mean values of the soil $\mathrm{pH}$ are 5.50 and 5.61 , respectively, and the range of soil $\mathrm{pH}$ is $4.30-7.80$, thereby indicating that the soil in the studied area is mostly acidic.

Table 3. Descriptive statistical summary of concentrations of heavy metals in soil and rice samples.

\begin{tabular}{cccccccccccc}
\hline Statistical Measures & $\mathbf{C d}$ & $\mathbf{H g}$ & $\mathbf{A s}$ & $\mathbf{P b}^{\mathbf{1}}$ & $\mathbf{C r}$ & $\mathbf{p H}$ & $\mathbf{C d}^{\mathbf{2}}$ & $\mathbf{H g}^{\mathbf{2}}$ & $\mathbf{A s}^{\mathbf{2}}$ & $\mathbf{P b}^{\mathbf{2}}$ & $\mathbf{C r}^{\mathbf{2}}$ \\
\hline Minimum & 0.17 & 0.06 & 5.10 & 22.00 & 40.30 & 4.30 & 0.00 & 0.00 & 0.00 & 0.00 & 0.00 \\
Maximum & 128.40 & 1.32 & 149.20 & 265.50 & 327.30 & 7.80 & 6.21 & 0.01 & 0.98 & 1.22 & 3.20 \\
Median & 0.55 & 0.15 & 17.10 & 44.30 & 70.50 & 5.50 & 0.28 & 0.01 & 0.08 & 0.00 & 0.08 \\
Mean & 0.97 & 0.17 & 18.29 & 48.54 & 74.58 & 5.61 & 0.46 & 0.01 & 0.09 & 0.02 & 0.23 \\
SD & 4.48 & 0.10 & 8.87 & 17.62 & 25.61 & 0.57 & 0.57 & 0.00 & 0.05 & 0.06 & 0.35 \\
CV (\%) & 461.42 & 56.96 & 48.50 & 36.29 & 34.33 & 10.11 & 123.40 & 42.59 & 62.24 & 233.46 & 155.19 \\
Kurtosis & 698.05 & 48.11 & 80.49 & 39.50 & 31.85 & 1.14 & 18.99 & -0.56 & 72.29 & 206.86 & 18.76 \\
Skewness & 24.97 & 5.40 & 6.98 & 4.69 & 4.43 & 0.78 & 3.40 & 0.19 & 4.69 & 11.40 & 3.52 \\
\hline
\end{tabular}

${ }^{1}$ Measured concentration of each heavy metal in the soil sample $(\mathrm{mg} / \mathrm{kg}) ;{ }^{2}$ measured concentration of each heavy metal in the rice sample $(\mathrm{mg} / \mathrm{kg})$.

The concentration histograms of the heavy metals in the soil and rice samples (Figure 6) are generated by the statistical package of the open-source software $\mathrm{R}$ to clearly demonstrate the concentration distribution characteristics of each heavy metal [58]. Figure 6 shows that the concentration distributions of the heavy metals in the soil and rice have exact skewness. However, the concentration distributions of $\mathrm{Hg}, \mathrm{Pb}$, and $\mathrm{CR}$ in the rice are not balanced, thus indicating a difference in the transfer and accumulation characteristics of the different heavy metals in the rice. Figure 7 shows that the concentration distribution curve of the $\mathrm{pH}$ coincides with the approximate norm distribution curve in Figure 7a. The points on the $\mathrm{Q}-\mathrm{Q}$ plot approximates to a straight line in Figure 7b, showing that the concentration distribution of the soil $\mathrm{pH}$ value is approximately normal.

The Pearson correlation coefficient between the concentration of the heavy metals and the $\mathrm{pH}$ in the soil and rice is obtained by using DPS software [57] (Table 4). A significantly positive correlation at the 0.01 level exists between variables $\mathrm{Cd}^{1}$ and $\mathrm{Cd}^{2}$, with the correlation coefficient being 0.220 . That is, the concentrations of $\mathrm{Cd}$ in the soil and rice have a significantly positive correlation at the 0.01 level. In a similar way, the correlation coefficient is 0.384 between variables $\mathrm{Pb}^{1}$ and $\mathrm{Pb}^{2}$ at the 0.01 level of significance. That is, the concentrations of $\mathrm{Cd}$ in the soil and rice have a significantly positive correlation at the 0.01 level. The concentrations of $\mathrm{Cd}$ in rice $\left(\mathrm{Cd}^{2}\right)$ and $\mathrm{Pb}$ in soil $\left(\mathrm{Pb}^{1}\right)$ and the concentrations of $\mathrm{Hg}$ in soil $\left(\mathrm{Hg}^{1}\right)$ and $\mathrm{Pb}$ in soil $\left(\mathrm{Pb}^{1}\right)$ also show a significantly negative correlation at the 0.01 level, respectively. By contrast, the concentrations of $\mathrm{Hg}$ in soil and rice $\left(\mathrm{Hg}^{1}\right.$ and $\mathrm{Hg}^{2}$, respectively) have a significantly negative correlation at the 0.01 level. In addition, the concentration of $\mathrm{Cd}$ in rice $\left(\mathrm{Cd}^{2}\right)$ and the $\mathrm{pH}$ value of the soil $\left(\mathrm{pH}^{1}\right)$ show a significantly negative correlation at the 0.01 level, with the correlation coefficient being -0.181 . This result indicates that a high soil $\mathrm{pH}$ equates to the low binding ability of $\mathrm{Cd}$ in rice. 
Table 4. Correlation coefficient matrix of concentrations of heavy metals in soil and rice samples.

\begin{tabular}{|c|c|c|c|c|c|c|c|c|c|c|c|}
\hline & $C d^{1}$ & $\mathrm{Hg}^{1}$ & $\mathrm{As}^{1}$ & $\mathrm{~Pb}^{1}$ & $\mathrm{Cr}^{1}$ & $\mathrm{pH}^{1}$ & $\mathrm{Cd}^{2}$ & $\mathrm{Hg}^{2}$ & $\mathrm{As}^{2}$ & $\mathrm{~Pb}^{2}$ & $\mathrm{Cr}^{2}$ \\
\hline $\mathrm{Hg}^{1}$ & $0.071 *$ & 1 & & & & & & & & & \\
\hline $\mathrm{Pb}^{1}$ & $0.135^{* *}$ & $0.383^{* *}$ & $0.310^{* *}$ & 1 & & & & & & & \\
\hline $\mathrm{Cr}^{1}$ & 0.015 & 0.068 & 0.023 & 0.034 & 1 & & & & & & \\
\hline $\mathrm{pH}^{1}$ & 0.017 & -0.054 & -0.012 & $-0.182^{* *}$ & $-0.205^{* *}$ & 1 & & & & & \\
\hline $\mathrm{As}^{2}$ & 0.014 & $0.201^{* *}$ & 0.079 * & $0.104^{* *}$ & -0.013 & $-0.079 *$ & -0.051 & $-0.180 * *$ & 1 & & \\
\hline $\mathrm{Pb}^{2}$ & $0.082 *$ & $0.127^{* *}$ & $0.106^{* *}$ & $0.384^{* *}$ & -0.037 & -0.037 & $0.214^{* *}$ & -0.056 & $0.115^{* *}$ & 1 & \\
\hline $\mathrm{Cr}^{2}$ & -0.021 & -0.056 & 0.059 & -0.015 & -0.048 & $0.149^{* *}$ & -0.003 & $0.113^{* *}$ & 0.084 * & 0.031 & 1 \\
\hline
\end{tabular}

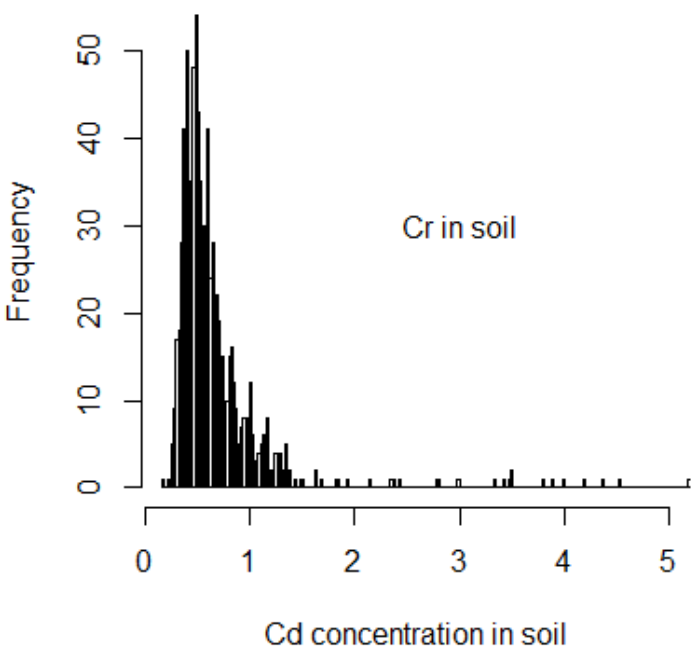

(a1)

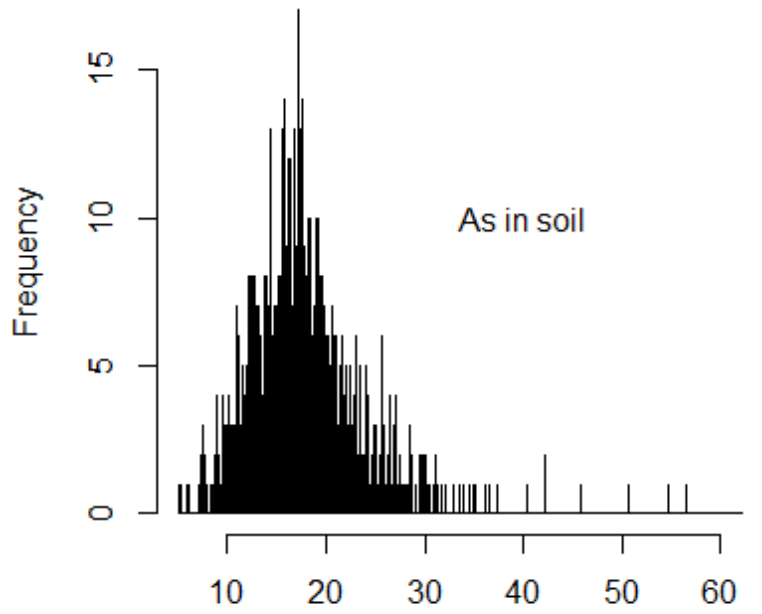

As concentration in soil

(c1)

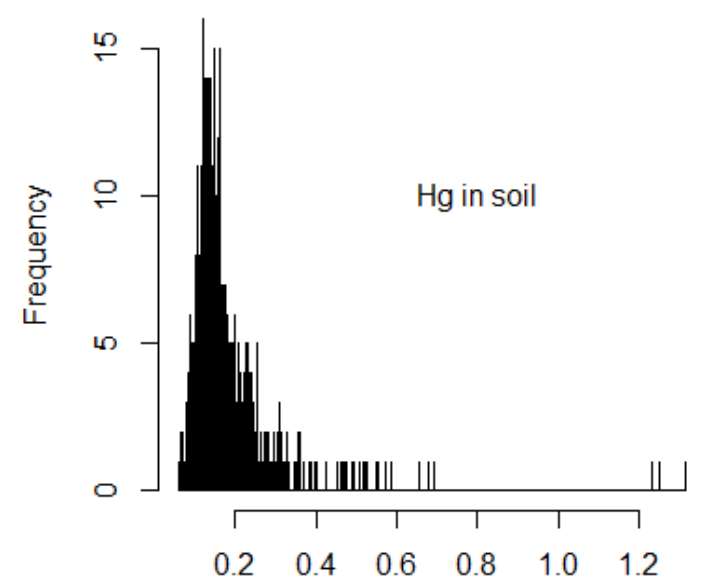

$\mathrm{Hg}$ concentration in soil

(b1)

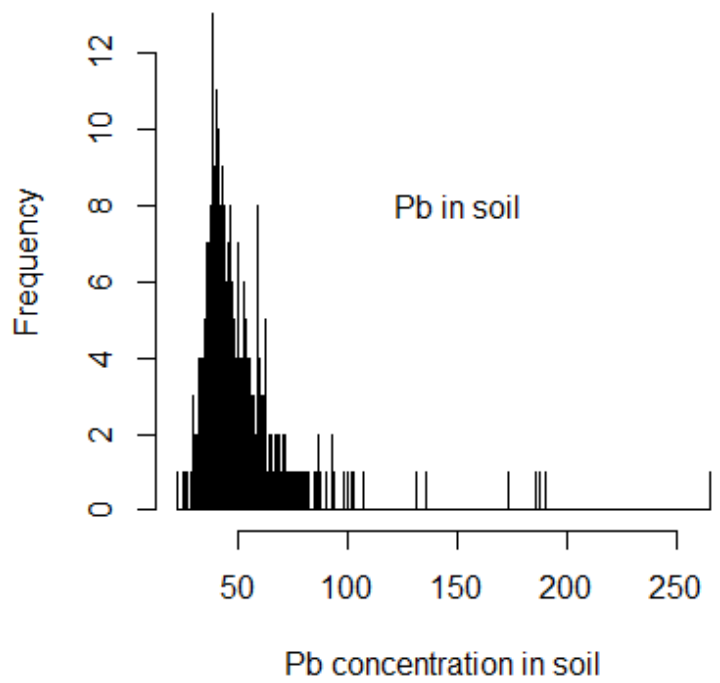

(d1)

Figure 6. Cont. 


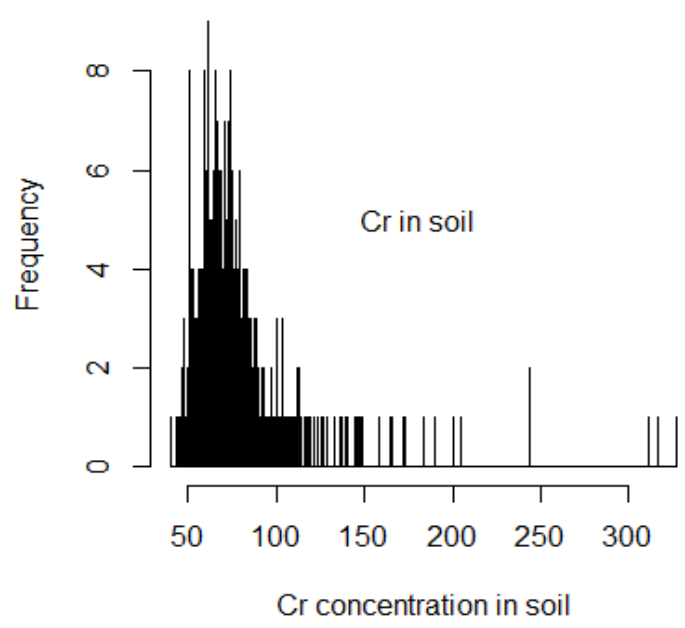

(e1)

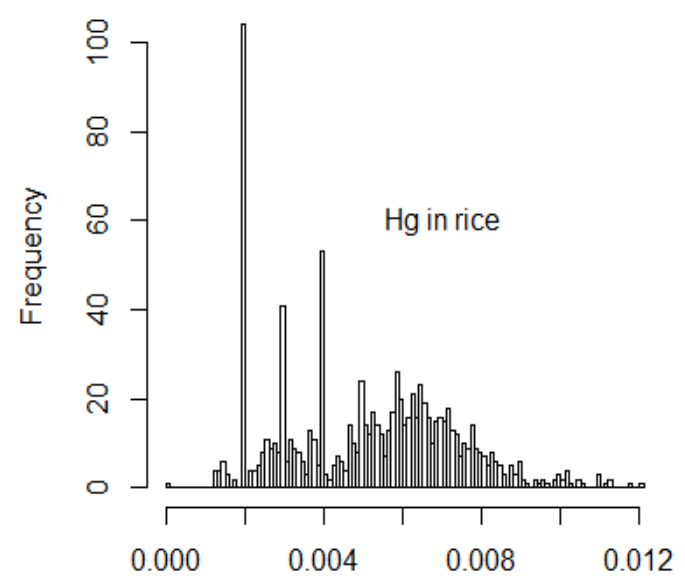

$\mathrm{Hg}$ concentration in rice

(b2)

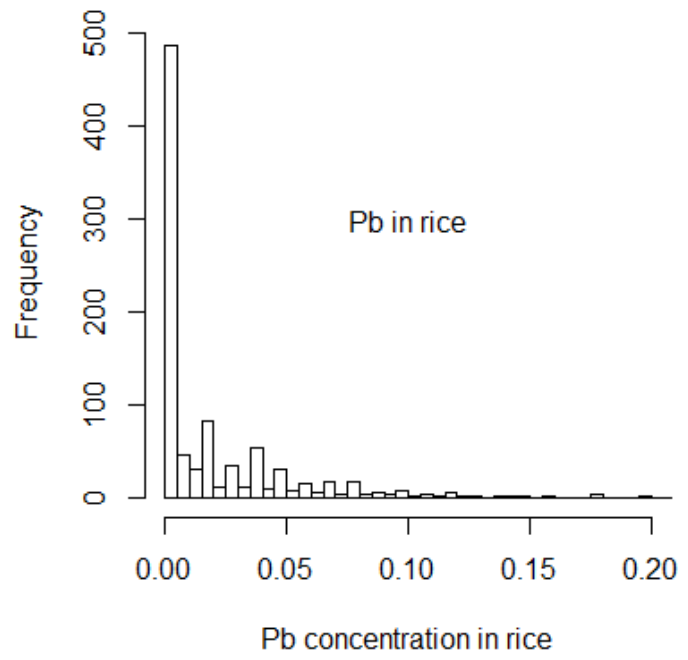

(d2)

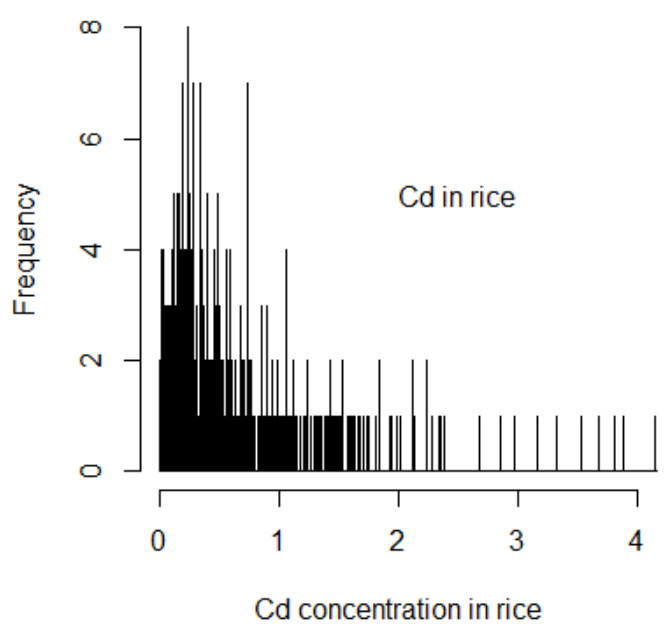

(a2)

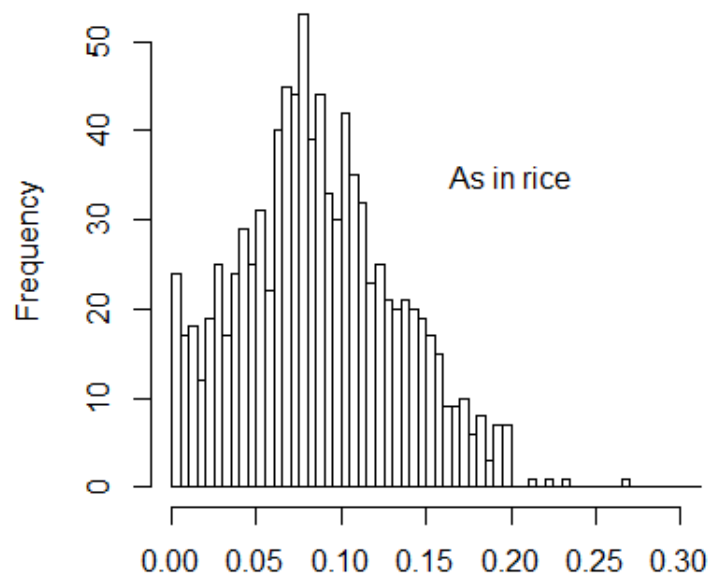

As concentration in rice

(c2)

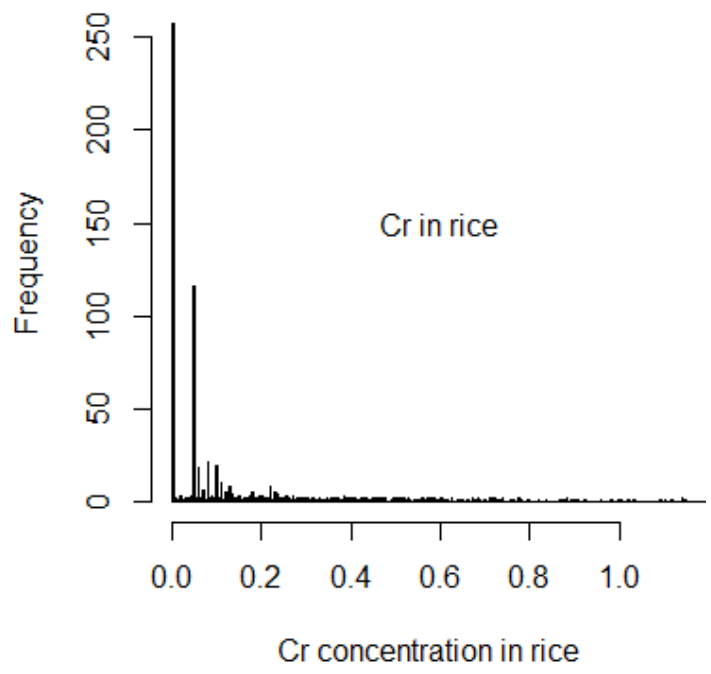

(e2)

Figure 6. Histograms of concentration distribution of each heavy metal in soil and rice samples; the horizontal axis denotes the concentration of heavy metal in the sample $(\mathrm{mg} / \mathrm{kg})$, and the vertical axis denotes the number of monitoring points. In soil: (a1) Cd; (b1) $\mathrm{Hg}$; (c1) As; (d1) $\mathrm{Pb}$; and (e1) Cr. In rice: (a2) $\mathrm{Cd}$; (b2) $\mathrm{Hg}$; (c2) As; (d2) $\mathrm{Pb}$; and (e2) Cr. 


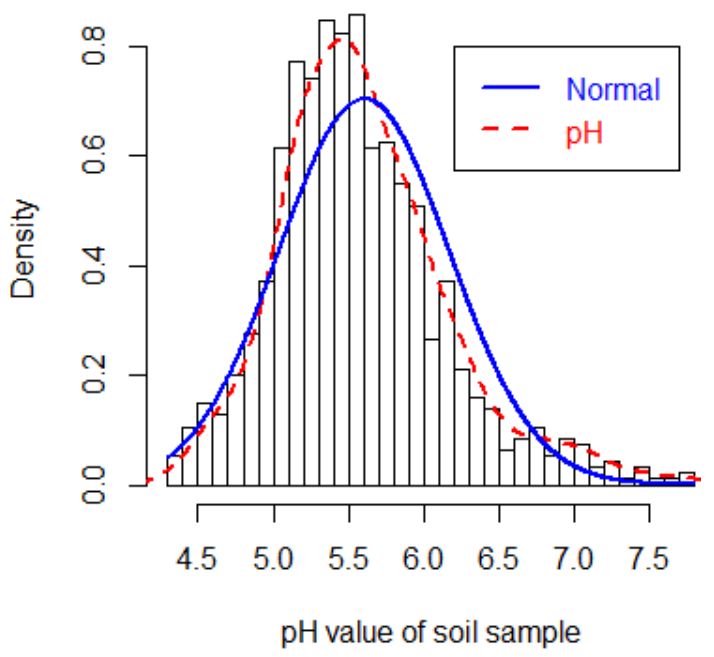

(a)

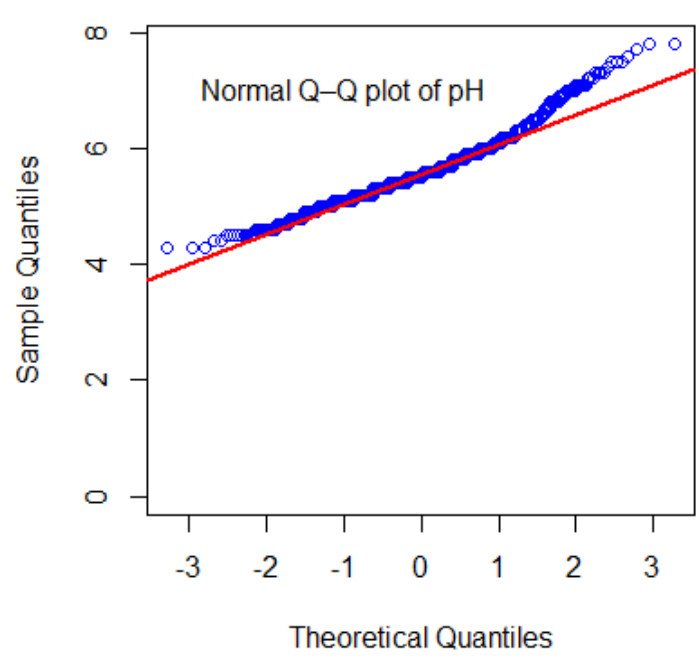

(b)

Figure 7. $\mathrm{pH}$ value distribution of soil samples: (a) histogram of $\mathrm{pH}$ value distribution in soil samples; and (b) normal $\mathrm{Q}-\mathrm{Q}$ plot of $\mathrm{pH}$ values in soil samples.

\subsection{Risk Assessment of Heavy Metal Pollution in Farmland Soils}

The number of monitoring points where the measured concentration of the heavy metals in the soil or rice samples exceeds the corresponding limit value is calculated prior to the risk assessment of heavy metal pollution in farmland soils. In this study, the limit values of the heavy metals in the farmland soils are determined by grade II limits of the Chinese national standard "Environmental Quality Standard of Soils (GB 15618-1995)" (Table 5), and the limit value of the heavy metals in the rice is determined by the Chinese national standard GB 2762-2017 (Table 6). The quantity and percentage of the monitoring points where the measured concentrations of the heavy metals in the soil or rice exceed the limit value stated by the national standard are presented in Table 7 . Soil Cd concentration exceeds its limit value in 929 monitoring points, which accounts for $98.31 \%$. Similarly, rice Cd concentration exceeds its limit value in 568 monitoring points, which accounts for $60.11 \%$. Meanwhile, soil $\mathrm{Hg}$ and $\mathrm{Cr}$ concentrations exceed their limit values in 50 (5.93\%) and 3 (0.32\%) monitoring points, respectively. Rice $\mathrm{Hg}$ and $\mathrm{Cr}$ concentrations exceed their limit values in 0 and 30 (3.17\%) monitoring points, respectively. Collectively, these results show that $\mathrm{Cd}$ is the most important pollutant in the farmland soils in the studied area and has the highest pollution rate in the soil (98.31\%) and rice $(60.11 \%)$, followed by $\mathrm{Hg}$, As, and $\mathrm{Pb}$, whose pollution rates are the lowest of the metals and are lower than $1 \%$ in the rice sample. These results suggest that $\mathrm{Cd}$ causes the most serious pollution in the farmland soil in the study area, followed by $\mathrm{Cr}, \mathrm{As}, \mathrm{Pb}$, and $\mathrm{Hg}$. Moreover, the concentrations of heavy metals, except for $\mathrm{Cd}$ and $\mathrm{Cr}$, in the farmland soil in the study area are tolerable or close to acceptable. However, some specific measures should still be adopted to reduce environmental exposure risks to soil metals and protect vulnerable populations, such as children and women [27]. Previous studies show that $\mathrm{Cd}$ and $\mathrm{Cr}$ are harmful to the human body, and this finding is supported by adequate evidence $[5,11-13,29]$. Special attention should be paid and control priority should be given to these two heavy metals to target the lowest threats to the safety of agricultural products and human health. Therefore, several soil remediation measures should be conducted for reducing $\mathrm{Cd}$ and $\mathrm{Cr}$ concentrations in the farmland soils of the studied area and reduce their accumulation in crops. 
Table 5. Limit values of heavy metals in farmland soils $(\mathrm{mg} / \mathrm{kg})$.

\begin{tabular}{cccc}
\hline Metals & $\mathbf{p H}<\mathbf{6 . 5}$ & $\mathbf{6 . 5} \leq \mathbf{p H} \leq \mathbf{7 . 5}$ & $\mathbf{p H}>\mathbf{7 . 5}$ \\
\hline $\mathrm{Cd} \leq$ & 0.3 & 0.3 & 0.6 \\
$\mathrm{Hg} \leq$ & 0.3 & 0.5 & 1 \\
$\mathrm{As} \leq$ & 30 & 25 & 20 \\
$\mathrm{~Pb} \leq$ & 250 & 300 & 350 \\
$\mathrm{Cr} \leq$ & 250 & 300 & 350 \\
\hline
\end{tabular}

Table 6. Limit values of heavy metals in rice $(\mathrm{mg} / \mathrm{kg})$.

\begin{tabular}{cccccc}
\hline Sample & $\mathbf{C d} \leq$ & $\mathbf{H g} \leq$ & As $\leq$ & $\mathbf{P b} \leq$ & $\mathbf{C r} \leq$ \\
\hline Rice & 0.20 & 0.02 & 0.20 & 0.20 & 1.00 \\
\hline
\end{tabular}

Table 7. Quantity and percentage of unqualified monitoring points.

\begin{tabular}{ccccccccccc}
\hline $\begin{array}{c}\text { Unqualified } \\
\text { Monitoring Points }\end{array}$ & $\mathbf{C d}{ }^{\mathbf{1}}$ & $\mathbf{H g}{ }^{\mathbf{1}}$ & $\mathbf{A s}{ }^{\mathbf{1}}$ & $\mathbf{P b}^{\mathbf{1}}$ & $\mathbf{C r} \mathbf{1}^{\mathbf{1}}$ & $\mathbf{C d}^{\mathbf{2}}$ & $\mathbf{H g}^{2}$ & $\mathbf{A s}^{2}$ & $\mathbf{P b}^{2}$ & $\mathbf{C r}^{2}$ \\
\hline $\begin{array}{c}\text { Quantity } \\
\text { Percentage (\%) }\end{array}$ & 929 & 56 & 32 & 1 & 3 & 568 & 0 & 5 & 4 & 30 \\
\hline \multicolumn{8}{c}{${ }^{1}$ In soil; ${ }^{2}$ in rice. }
\end{tabular}

In this study, our proposed soil-crop collaborative risk assessment model is applied for assessing the degree of heavy metal pollution in farmland soils. The percentage of monitoring points at each pollution level is calculated; Figure 8 shows that the proportions of monitoring points at each pollution level are $4.87 \%, 24.23 \%, 46.67 \%, 11.75 \%$, and $12.49 \%$, respectively. More than $70.9 \%$ of the farmland soils are slightly polluted (pollution level III) or above; $46.67 \%, 11.75 \%$, and $12.49 \%$ are lightly, moderately, and severely polluted, respectively. The proportions of farmland soils at pollution level I and II are $4.87 \%$ and $24.23 \%$, respectively. These findings indicate that most of the farmland soils in the studied area are polluted, and lightly polluted (pollution level III) farmland soils account for the largest proportion (46.67\%). The main causes of heavy metal pollution in soils are most often man-made and caused by increasing industrialization and human activities [27]. Many factors, such as mining and smelting, industry, sewage irrigation, urban development, and fertilizer application [27], contribute to the heavy metal pollution in the farmland soils of the studied area. The area is the center of Chinese nonferrous mining [29] and has abundant amounts of nonferrous metals in its soil. Human activities in this area, especially mining and sewage irrigation, release a large amount of heavy metals into the farmland soils.

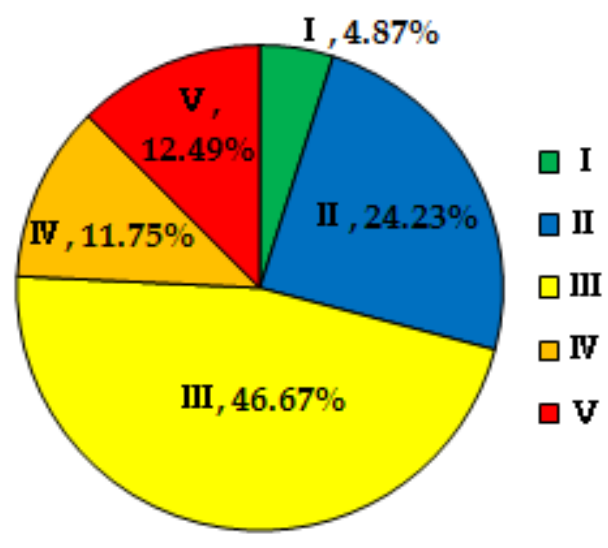

Figure 8. Proportions of monitoring points at each pollution level. 
The pollution risk assessment results of the traditional model and our collaborative model are compared to examine the performance of the latter. The pollution level of each monitoring point is determined, and the number of monitoring points at each pollution level is counted by using the two abovementioned risk assessment models. The comparison of the two models is presented in Table 8 and Figure 9. Table 8 shows that the slightly polluted (pollution level III) farmland soils account for a large proportion, reaching $63.28 \%$ using the traditional model and $46.67 \%$ using the collaborative model. The collaborative model produces lower proportions of lightly and moderately polluted farmland soils than the traditional model. However, excellent, good, and severely polluted farmland soils account for a high proportion under the collaborative model (Figure 9). This result suggests that the concentrations of the heavy metals in crops are similar to those in soil, albeit with some subtle differences. Given that different heavy metals have different transfer and accumulation characteristics in different crop varieties [55,56], the concentration of heavy metals in crops will also be different despite being in the same field soil growth. This condition implies that crop varieties that are resistant to heavy metals should be cultivated in areas that are slightly or moderately polluted by heavy metals. Meanwhile, food crops should be banned in severely polluted areas to prevent heavy metals from entering the human body.

Table 8. Comparison of pollution risk assessment results between traditional and collaborative models.

\begin{tabular}{ccccc}
\hline \multirow{2}{*}{ Pollution Level } & \multicolumn{2}{c}{ Traditional Model } & \multicolumn{2}{c}{ Collaborative Model } \\
\cline { 2 - 5 } & Quantity & Percentage (\%) & Quantity & Percentage (\%) \\
\hline I & 5 & 0.53 & 46 & 4.87 \\
II & 134 & 14.18 & 229 & 24.23 \\
III & 598 & 63.28 & 441 & 46.67 \\
IV & 140 & 14.81 & 111 & 11.75 \\
V & 68 & 7.20 & 118 & 12.49 \\
\hline
\end{tabular}

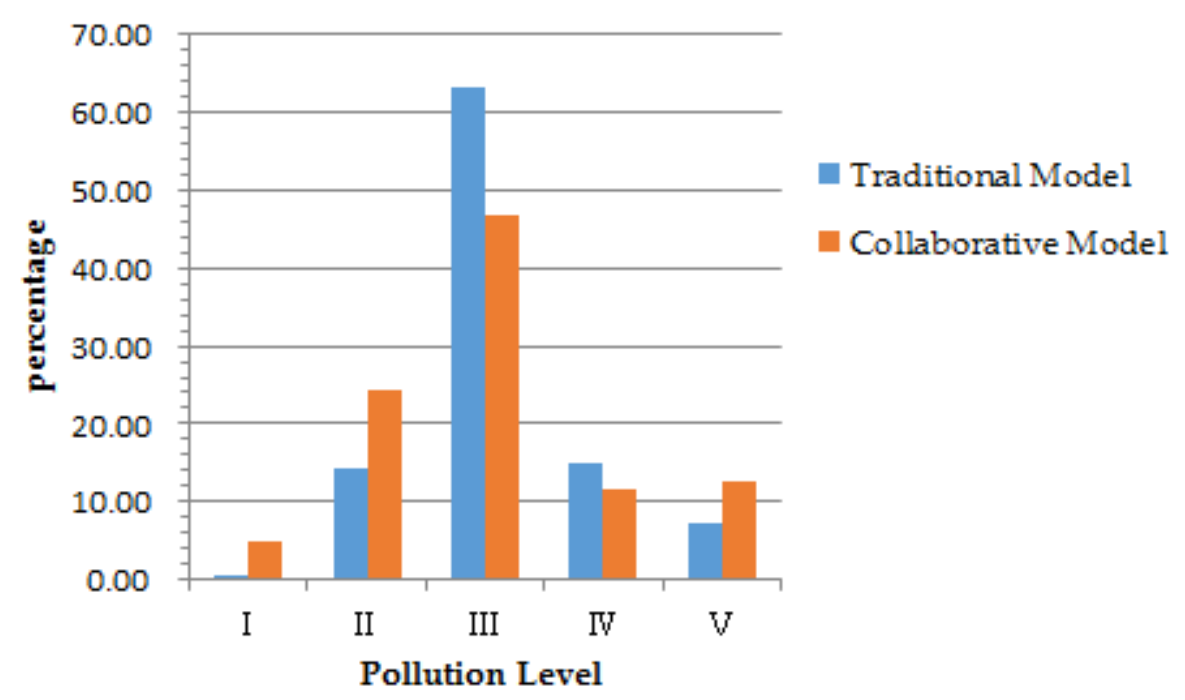

Figure 9. Comparison of pollution level percentages yielded by both models.

Finally, WebGIS technology, that is, Baidu Maps, is used to visually display the relevant information about heavy metal pollution in farmlands. The pollution risk level of each sampling point can be clearly marked on the spatial distribution map of the risk levels for heavy metal pollution in the monitoring points (Figure 10), which indicate that the middle eastern section of the study area has a high concentration of contamination hotspots. This area, which is close to the Xiang River is a traditional industrialized region with many mineral mining enterprises and chemical companies. Hence, industrial emissions, mining, smelting, and sewage irrigation, along with the original soil 
texture and composition, may be the main causes of heavy metal pollution in the soils in the study area. Moreover, the historical sampling data of each sampling point can also be easily retrieved. Users can easily access the abovementioned information via a desktop computer, a tablet, or a smartphone.

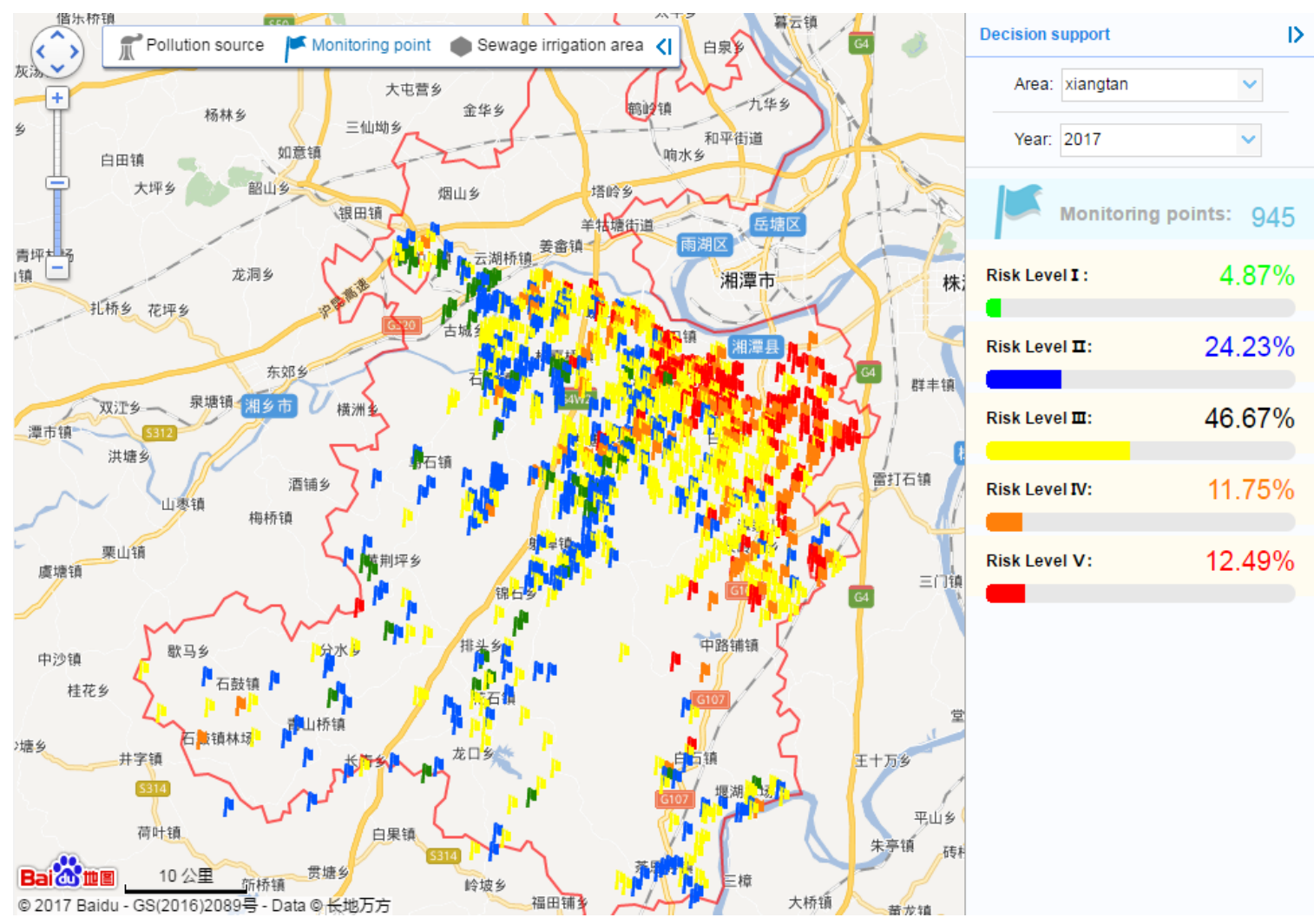

Figure 10. Map of risk levels for heavy metal pollution in monitoring points.

\subsection{Implementation}

Our proposed soil-crop collaborative assessment model is integrated into the WIS in the DSS-RAHMP. The WIS can provide various services, such as risk assessment, data management, and statistical analysis (Figure 11). Users can access the WIS through different user interfaces, such as desktop computers, laptops, and tablet PCs. Until now, the developed system is applied in several county-level cities in China for risk assessment and supervision of heavy metal pollution in farmland soils, with its functions, including risk assessment, data acquisition, statistical analysis, and agricultural survey. To date, our system is running safely and stably and can provide better decision support for the risk assessment of heavy metal pollution in farmlands than when no such system is applied. For instance, our developed data acquisition system can collect and upload data from monitoring points efficiently and accurately, and this system is considerably superior to the traditional way of paper collection. When data collection is complete, our system automatically assesses the pollution risk and visually displays the evaluation results on the map. Therefore, the level of soil heavy metal pollution at each monitoring point and its sampling data can be easily queried in real time. Government managers can adopt a series of measures, such as targeted monitoring, soil remediation, and crop adjustment, in areas at high risk of soil heavy metal pollution. Thus, these measures are valuable in improving the management level of heavy metal pollution in farmland soil. 


\section{Decision Support System for Heavy Metal Pollution in Farmland}

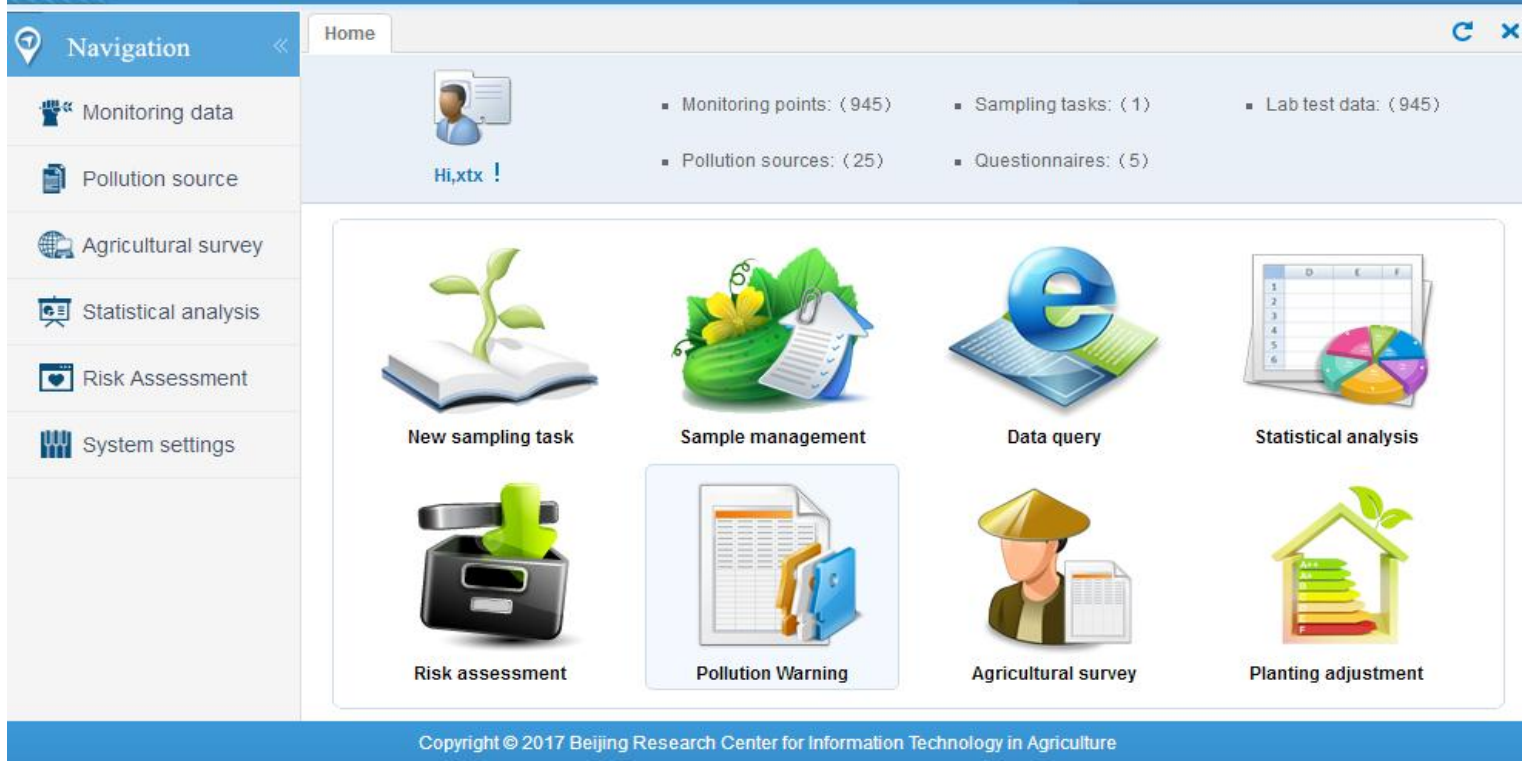

Figure 11. Home page of WIS in DSS-RAHMP.

\section{Conclusions}

Heavy metal pollution in farmland soils is a major concern in China. Heavy metal pollution in agricultural soil has adverse effects on soil ecosystem and causes potential food safety and health risks. Thus, a risk-oriented decision support system should be constructed for monitoring and assessing heavy metal pollution in farmland soils. In this study, the DSS-RAHMP is proposed and presented, and several techniques, namely, WebGIS, QR code, and RFID, are introduced in this framework. Then, a soil-crop collaborative risk assessment model, which considers the effect of heavy metal concentrations in soil and crops, is proposed for the risk assessment of heavy metal pollution in farmland soils. A soil sample and corresponding crop sample is collected from each of the 945 monitoring points in the studied area. Results show that $\mathrm{Cd}$ is the most important pollutant in farmland soils and has the highest unqualified rate of $98.31 \%$ in the soil samples and $60.11 \%$ in the rice samples. More than $70.9 \%$ of the farmland soils are slightly polluted or above in the studied area. Many factors, including natural and man-made factors, may cause heavy metal pollution in farmland soils. Heavy metal enrichment in soil can be the result of natural processes, such as the weathering of heavy metal-rich parent rocks and interactions between soil components, such as organic matter or clay content [24]. Furthermore, increasing industrialization and human activities greatly affect heavy metal pollution in soils [5]. Users can easily access the results of the risk assessment of the study area in many ways. For instance, the results are visually displayed on the WIS in the DSS-RAHMP, which provides different user interfaces. Our proposed system has been running steadily for over a year. The findings show that our proposed system framework and model can be applied for assessing the pollution of heavy metals in farmland soils.

Recently, many studies have focused on the assessment of heavy metal pollution [7,15,24-27,59]. Nevertheless, most of these works utilized theoretical or empirical methods in their study of soil heavy metal pollution. Only a few reports presented the construction of decision support systems for risk assessment for heavy metal pollution in farmland soils. Some studies explored information systems for heavy metal pollution in water and air $[60,61]$; however, most of them only described system designs or functions and did not present any implementation and application. Moreover, few successful implementations using information systems for risk assessment and management decision-making related to heavy metal pollution in farmland soils are reported in the Chinese industry. One reason 
for this deficiency is that the research on management and decision support systems for heavy metal pollution in farmlands in China is still in the exploratory stage. Another reason is that the existing information systems in this area are not powerful enough to meet the actual management needs for addressing heavy metal pollution in farmland soils. Our proposed system, which is composed of an MDAT and a WIS, can realize rapid collection and integration management of farmland soil monitoring data by integrating technologies such as WebGIS, QR code, RFID, and web services as bases. The analytical findings and their visual presentation from our proposed system can provide technical support for monitoring and supervising heavy metal pollution in farmland soils. Users can query the risk assessment results and historical sampling data of each monitoring point in real time. Few supervisors can monitor the dynamic changes of all monitoring points in a county. Traditionally, such work is impossible without the support of an information system. The proposed system effectively solves problems such as backward monitoring means, low informatization level, high cost, and low efficiency of management in the supervision of heavy metal pollution in farmland soils. Hence, the proposed system can help improve the level of automation and intelligence of the supervision of heavy metal pollution in farmland soils. The system is employed in several county-level cities in China for managing heavy metal pollution in farmlands, with its functions, including risk assessment, data acquisition, statistical analysis, and agricultural survey. The practical applications of the system are beneficial for the improvement of farmland soil environment management and heavy metal pollution prevention and control. Consequently, this study offers scientific and practical implications through the proposed WebGIS-based risk assessment system for heavy metal pollution in farmland soils. Our proposed soil-crop collaborative risk assessment model can objectively evaluate the heavy metal pollution in farmland soils in comparison with the traditional assessment models considering only soil samples. In addition, our research work may provide valuable references for governmental agencies to initiate and adjust relevant policies for preventing and controlling heavy metal pollution in farmland soils in China.

However, we should emphasize that this research has some limitations. The study is conducted from a technical point of view and focused on developing a risk assessment system for soil heavy metal pollution. Non-technical factors, such as political, socioeconomic, and legal issues [19], which may also lead to heavy metal pollution in farmland soils [59], were not considered in the risk assessment. Moreover, uncertainties may exist in risk assessment due to the low optimization of the layout of monitoring points and random sampling errors. In addition, the functional modules of our system need to be further extended and optimized.

For future research, we will concentrate on the following: (1) improving the risk assessment method (e.g., considering non-technical factors) to make it highly scientific and objective and upgrading the information system to satisfy the needs of users and support massive and complex datasets; (2) creating an early warning model for heavy metal pollution in farmland soils; and (3) creating a crop-planting adjustment model for seriously polluted farmland soils.

Acknowledgments: This research is supported by the Beijing Natural Science Foundation (No. 9152009), the National Natural Science Foundation of China (Nos. 71301011 and 61403035), and the National Key Research and Development Program of China (No. 2016YFD0800907). The authors would like to thank all of the researchers for their efforts in our work. We also thank the reviewers and editors for their valuable suggestions and comments to improve this work.

Author Contributions: Shouhui Pan conceived this research and wrote the paper; Zhibin Wang and Yanyun Han carried out the data collection and processing; Shouhui Pan and Kaiyi Wang developed the information system and conducted the discussion; and Kaiyi Wang and Li Wang designed this research and provided important advice for paper promotion.

Conflicts of Interest: The authors declare no conflict of interest. 


\section{References}

1. Wang, Y.D.; Roijakkers, N.; Vanhaverbeke, W.; Chen, J. How Chinese firms employ open innovation to strengthen their innovative performance. Int. J. Technol. Manag. 2012, 59, 235-254. [CrossRef]

2. Li, Y.R.; Wang, J.; Liu, Y.S.; Long, H.L. Problem regions and regional problems of socioeconomic development in China: A perspective from the coordinated development of industrialization, informatization, urbanization and agricultural modernization. J. Geogr. Sci. 2014, 24, 1115-1130. [CrossRef]

3. Norse, D.; Ju, X.T. Environmental costs of China's food security. Agric. Ecosyst. Environ. 2015, 209, 5-14. [CrossRef]

4. Dong, X.Y.; Song, S.F.; Zhang, X.B.; Qiu, H.G. China's agricultural development: Challenges and prospects. Eur. Rev. Agric. Econ. 2007, 34, 421-424.

5. Hu, H.; Jin, Q.; Kavan, P. A Study of Heavy Metal Pollution in China: Current Status, pollution-control policies and countermeasures. Sustainability 2014, 6, 5820-5838. [CrossRef]

6. Ding, F.H.; He, Z.L.; Liu, S.X.; Zhang, S.H.; Zhao, F.L.; Li, Q.F.; Stoffella, P.J. Heavy metals in composts of China: Historical changes, regional variation, and potential impact on soil quality. Environ. Sci. Pollut. Res. 2017, 24, 3194-3209. [CrossRef] [PubMed]

7. Qu, C.S.; Sun, K.; Wang, S.R.; Huang, L.; Bi, J. Monte Carlo Simulation-Based Health Risk Assessment of Heavy Metal Soil Pollution: A Case Study in the Qixia Mining Area, China. Hum. Ecol. Risk Assess. 2012, 18, 733-750. [CrossRef]

8. Gu, Y.G.; Li, Q.S.; Fang, J.H.; He, B.Y.; Fu, H.B.; Tong, Z.J. Identification of heavy metal sources in the reclaimed farmland soils of the pearl river estuary in China using a multivariate geostatistical approach. Ecotoxicol. Environ. Saf. 2014, 105, 7-12. [CrossRef] [PubMed]

9. Liu, L. Made in China: Cancer villages. Environ. Sci. Policy Sustain. Dev. 2010, 52, 8-21. [CrossRef]

10. Salem, H.M.; Eweida, E.A.; Farag, A. Heavy metals in drinking water and their environmental impact on human health. In Proceedings of the International Conference for Environmental Hazard Mitigation ICEHM 2000, Cairo University, Giza, Egypt, 9-12 September 2000; pp. 542-556.

11. Sarkar, B. Heavy Metals in the Environment. CRC Press: Boca Raton, FL, USA, 2002.

12. Duruibe, J.O.; Ogwuegbu, M.O.C.; Egwurugwu, J.N. Heavy metal pollution and human biotoxic effects. Int. J. Phys. Sci. 2007, 2, 112-118.

13. Liu, Y.; Chen, M.M.; Jiang, L.G.; Song, L. New insight into molecular interaction of heavy metal pollutant-cadmium(II) with human serum albumin. Environ. Sci. Pollut. Res. 2014, 21, 6994-7005. [CrossRef] [PubMed]

14. Si, W.T.; Liu, J.M.; Cai, L.; Jiang, H.M.; Zheng, C.L.; He, X.Y.; Wang, J.Y.; Zhang, X.F. Health Risks of Metals in Contaminated Farmland Soils and Spring Wheat Irrigated with Yellow River Water in Baotou, China. Bull. Environ. Contam. Toxicol. 2015, 94, 214-219. [CrossRef] [PubMed]

15. Wan, X.M.; Lei, M.; Chen, T.B.; Tan, Y.B.; Yang, J.X. Safe utilization of heavy-metal-contaminated farmland by mulberry tree cultivation and silk production. Sci. Total Environ. 2017, 599, 1867-1873. [CrossRef] [PubMed]

16. Qureshi, A.S.; Hussain, M.I.; Ismail, S.; Khan, Q.M. Evaluating heavy metal accumulation and potential health risks in vegetables irrigated with treated wastewater. Chemosphere 2016, 163, 54-61. [CrossRef] [PubMed]

17. Leading leaden lives. China Daily. 06 August 2014. Available online: http:/ /www.chinadaily.com.cn/201408/06/content_18255497.htm (accessed on 3 August 2017).

18. Cadmium Pollution to Affect 300-km Section of River in Guangxi. China Daily. 31 January 2012. Available online: http:/ / www.chinadaily.com.cn/bizchina/2012-01/31/content_14512806.htm (accessed on 3 August 2017).

19. Li, H.X.; Li, Y.R.; Lee, M.K.; Liu, Z.W.; Miao, C.H. Spatiotemporal Analysis of heavy metal water pollution in transitional China. Sustainability 2015, 7, 9067-9087. [CrossRef]

20. Ministry of Environmental Protection of China. National Investigation Communique on Soil Pollution. Available online: http://www.zhb.gov.cn/gkml/hbb/qt/201404/t20140417_270670.htm (accessed on 10 August 2017).

21. The State Council of China. Efforts to Prevent and Remedy Soil Pollution. Available online: http:/ / english. gov.cn/policies / latest_releases/2016/05/31/content_281475361737430.htm (accessed on 10 August 2017). 
22. Zhang, X.Y.; Zhong, T.Y.; Liu, L.; Ouyang, X.Y. Impact of Soil Heavy Metal Pollution on Food Safety in China. PLOS ONE 2015, 10, e0135182. [CrossRef] [PubMed]

23. Tang, X.; Li, Q.; Wu, M.; Lin, L.; Scholz, M. Review of remediation practices regarding cadmium-enriched farmland soil with particular reference to China. J. Environ. Manag. 2016, 181, 646-662. [CrossRef] [PubMed]

24. Gasiorek, M.; Kowalska, J.; Mazurek, R.; Pajak, M. Comprehensive assessment of heavy metal pollution in topsoil of historical urban park on an example of the Planty Park in Krakow (Poland). Chemosphere 2017, 179, 148-158. [CrossRef] [PubMed]

25. Xiao, Q.; Zong, Y.T.; Lu, S.G. Assessment of heavy metal pollution and human health risk in urban soils of steel industrial city (Anshan), Liaoning, Northeast China. Ecotoxicol. Environ. Saf. 2015, 120, 377-385.

26. Cai, C.; Xiong, B.J.; Zhang, Y.C.; Li, X.H.; Nunes, L.M. Critical Comparison of Soil Pollution Indices for Assessing Contamination with Toxic Metals. Water Air Soil Pollut. 2015, 226, 1-14. [CrossRef]

27. Chen, H.Y.; Teng, Y.G.; Lu, S.J.; Wang, Y.Y.; Wang, J.S. Contamination features and health risk of soil heavy metals in China. Sci. Total Environ. 2015, 512, 143-153. [CrossRef] [PubMed]

28. Zhuang, W.; Liu, Y.X.; Chen, Q.; Wang, Q.; Zhou, F.X. A new index for assessing heavy metal contamination in sediments of the Beijing-Hangzhou Grand Canal (Zaozhuang Segment): A case study. Ecol. Indic. 2016, 69, 252-260. [CrossRef]

29. Wang, Z.X.; Chen, J.Q.; Chai, L.Y.; Yang, Z.H.; Huang, S.H.; Zheng, Y. Environmental impact and site-specific human health risks of chromium in the vicinity of a ferro-alloy manufactory, China. J. Hazard. Mater. 2011, 190, 980-985. [CrossRef] [PubMed]

30. Carr, R.; Zhang, C.S.; Moles, N.; Harder, M. Identification and mapping of heavy metal pollution in soils of a sports ground in Galway City, Ireland, using a portable XRF analyser and GIS. Environ. Geochem. Health 2008, 30, 45-52. [CrossRef] [PubMed]

31. Borges, R.C.; Caldas, V.G.; Simoes, F.F.L.; Ferreira, M.M.; Lapa, C.M.F. Use of GIS for the evaluation of heavy metal contamination in the Cunha Canal watershed and west the Guanabara Bay, Rio de Janeiro, RJ. Mar. Pollut. Bull. 2014, 89, 75-84. [CrossRef] [PubMed]

32. Shan, Y.S.; Tysklind, M.; Hao, F.H.; Ouyang, W.; Chen, S.Y.; Lin, C.Y. Identification of sources of heavy metals in agricultural soils using multivariate analysis and GIS. J. Soils Sediments 2013, 13, 720-729. [CrossRef]

33. Amous, M.O.; Hassan, M.A.A. Heavy metals risk assessment in water and bottom sediments of the eastern part of Lake Manzala, Egypt, based on remote sensing and GIS. Arab. J. Geosci. 2015, 8, 7899-7918.

34. Tiwari, A.K.; Singh, P.K.; Singh, A.K.; De Maio, M. Estimation of Heavy Metal Contamination in Groundwater and Development of a Heavy Metal Pollution Index by Using GIS Technique. Bull. Environ. Contam. Toxicol. 2016, 96, 508-515. [CrossRef] [PubMed]

35. Pan, S.H.; Wang, L.; Wang, K.Y.; Bi, Z.M.; Shan, S.Q.; Xu, B. A knowledge engineering framework for identifying key impact factors from safety-related accident cases. Syst. Res. Behav. Sci. 2014, 31, 383-397. [CrossRef]

36. Monte, L.; Brittain, J.E.; Gallego, E.; Hakanson, L.; Hofman, D.; Jimenez, A. MOIRA-PLUS: A decision support system for the management of complex fresh water ecosystems contaminated by radionuclides and heavy metals. Comput. Geosci. UK 2009, 35, 880-896. [CrossRef]

37. Horn, A.L.; During, R.A.; Gath, S. Comparison of decision support systems for an optimised application of compost and sewage sludge on agricultural land based on heavy metal accumulation in soil. Sci. Total Environ. 2003, 311, 35-48. [CrossRef]

38. Shi, J.Z.; Guo, J.E.; Fung, R.Y.K. Decision support system for purchasing management of seasonal products: A capital-constrained retailer perspective. Expert Syst. Appl. 2017, 80, 171-182. [CrossRef]

39. Sabzi, H.Z.; King, J.P.; Abudu, S. Developing an intelligent expert system for streamflow prediction, integrated in a dynamic decision support system for managing multiple reservoirs: A case study. Expert Syst. Appl. 2017, 83, 145-163. [CrossRef]

40. Tang, H.; Lee, C.B.P.; Choong, K.K. Consumer decision support systems for novice buyers-A design science approach. Inf. Syst. Front. 2017, 19, 881-897. [CrossRef]

41. Shin, S.J.; Kim, D.B.; Shao, G.D.; Brodsky, A.; Lechevalier, D. Developing a decision support system for improving sustainability performance of manufacturing processes. J. Intell. Manuf. 2017, 28, 1421-1440. [CrossRef]

42. Shah, M.A.R.; Rahman, A.; Chowdhury, S.H. Sustainability assessment of flood mitigation projects: An innovative decision support framework. Int. J. Disaster Risk Reduct. 2017, 23, 53-61. [CrossRef] 
43. Lopez, J.C.L.; Carrillo, P.A.A.; Chavira, D.A.G.; Noriega, J.J.S. A web-based group decision support system for multicriteria ranking problems. Oper. Res. Ger. 2017, 17, 499-534.

44. Cortez, R.; Vazhenin, A. Virtual model-view-controller design pattern: Extended MVC for service-oriented architecture. IEEJ Trans. Electr. Electron. 2015. [CrossRef]

45. Spring Framework. Available online: http://projects.spring.io/spring-framework/ (accessed on 10 August 2017).

46. Hibernate ORM Downloads. Available online: http:/ / hibernate.org/orm/ (accessed on 10 August 2017).

47. Welcome to the Apache Struts Project. Available online: http://struts.apache.org/ (accessed on 10 August 2017).

48. SiteMesh 3 Overview. Available online: http://wiki.sitemesh.org/wiki/display/sitemesh3/Home (accessed on 10 August 2017).

49. Welcome to Apache Maven. Available online: http://maven.apache.org/ (accessed on 10 August 2017).

50. Fdez-Riverola, F.; Glez-Pena, D.; Lopez-Fernandez, H.; Reboiro-Jato, M.; Mendez, J.R. A JAVA application framework for scientific software development. Softw. Pract. Exp. 2012, 42, 1015-1036. [CrossRef]

51. Kim, Y.G.; Woo, E. Consumer acceptance of a quick response (QR) code for the food traceability system: Application of an extended technology acceptance model (TAM). Food Res. Int. 2016, 85, 266-272. [CrossRef]

52. Han, Y.Y.; Wang, K.Y.; Liu, Z.Q.; Zhang, Q.; Pan, S.H.; Zhao, X.Y.; Wang, S.F. A crop trait information acquisition system with multitag-based identification technologies for breeding precision management. Comput. Electron. Agr. 2017, 135, 71-80. [CrossRef]

53. Mehrjerdi, Y.Z. RFID-enabled systems: A brief review. Assem. Autom. 2008, 28, 235-245. [CrossRef]

54. Yang, S.Y. Developing an energy-saving and case-based reasoning information agent with Web service and ontology techniques. Expert Syst. Appl. 2013, 40, 3351-3369. [CrossRef]

55. Xu, P.; Sun, C.X.; Ye, X.Z.; Xiao, W.D.; Zhang, Q.; Wang, Q. The effect of biochar and crop straws on heavy metal bioavailability and plant accumulation in a $\mathrm{Cd}$ and $\mathrm{Pb}$ polluted soil. Ecotoxicol. Environ. Saf. 2016, 132, 94-100. [CrossRef] [PubMed]

56. Balkhair, K.S.; Ashraf, M.A. Field accumulation risks of heavy metals in soil and vegetable crop irrigated with sewage water in western region of Saudi Arabia. Saudi J. Biol. Sci. 2016, 23, S32-S44. [CrossRef] [PubMed]

57. Tang, Q.Y.; Zhang, C.X. Data Processing System (DPS) software with experimental design, statistical analysis and data mining developed for use in entomological research. Insect Sci. 2013, 20, 254-260. [CrossRef] [PubMed]

58. The R Project for Statistical Computing. Available online: http://www.r-project.org/ (accessed on 5 August 2017).

59. Alfaro, M.R.; Montero, A.; Ugarte, O.M.; do Nascimento, C.W.A.; Accioly, A.M.D.; Biondi, C.M.; da Silva, Y.J.A.B. Background concentrations and reference values for heavy metals in soils of Cuba. Environ. Monit. Assess. 2015, 187, 1-10. [CrossRef] [PubMed]

60. Jiang, X.L.; Xiong, Z.Q.; Liu, H.; Liu, G.H.; Liu, W.Z. Distribution, source identification, and ecological risk assessment of heavy metals in wetland soils of a river-reservoir system. Environ. Sci. Pollut. Res. 2017, 24, 436-444. [CrossRef] [PubMed]

61. Song, K.H.; Choi, K.Y.; Kim, C.J.; Kim, Y.I.; Chung, C.S. Assessment of the governance system for the management of the East Sea-Jung dumping site, Korea through analysis of heavy metal concentrations in bottom sediments. Ocean Sci. J. 2015, 50, 721-740. [CrossRef]

(C) 2017 by the authors. Licensee MDPI, Basel, Switzerland. This article is an open access article distributed under the terms and conditions of the Creative Commons Attribution (CC BY) license (http:/ / creativecommons.org/licenses/by/4.0/). 